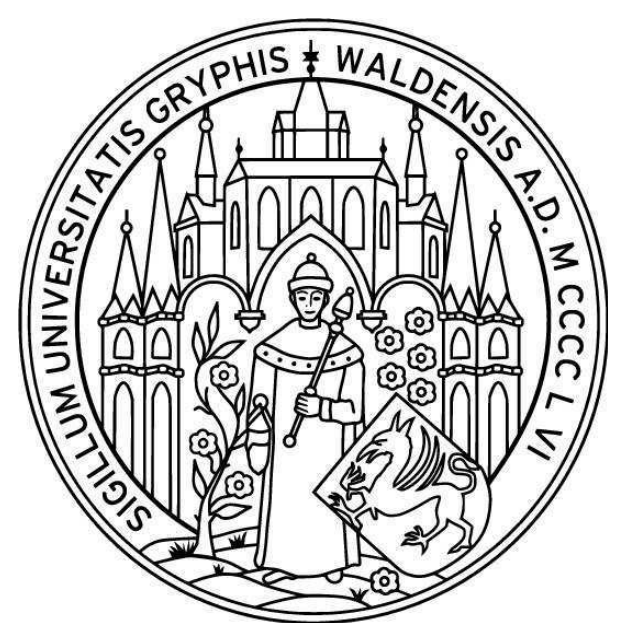

\title{
Plant diversity patterns at different spatial scales in a semi-arid savanna ecosystem in central Namibia
}

\author{
Jan Peters \\ Diploma Thesis \\ Landscape Ecology \& Nature Conservation \\ Ernst-Moritz-Arndt-Universität Greifswald \\ October 2010
}

Supervised by: Prof. Dr. Michael Manthey (University of Greifswald)

Dr. Jürgen Dengler (University of Hamburg) 



\section{Preface}

In 2008, I had the chance to gather my first experiences on the African continent during an internship in Senegal. Returning home with a passion for the African nature, the landscapes and especially the people, the decision to work in this region again in the course of my further studies matured in my mind. This wish was fulfilled in the year 2009 when I got the opportunity to participate in the BIOTA project as a field assistant at the vegetation monitoring of various Observatories in Namibia. At the same time, I had the possibility to conduct my own field work as the basis for this thesis. The working group 'Biodiversity, Evolution, and Ecology of Plants' at the Biocentre Klein Flottbek of the University of Hamburg faciliated the journey. Its staff works on the vegetation ecological part within the BIOTA subproject in southern Africa. Their research focuses are biodiversity patterns, their determining environmental factors and vegetation dynamics due to land use changes and climate change; therefore the topic of my thesis fits well into this context.

In order to make the results of this thesis available for the international scientific community, it is written in the style of a scientific publication and in English language. For a better understanding, a German summary is preceded. In the course of the work process, the different parts of my study turned out to be so thematically different, that I decided together with my supervisors to treat them all as separate scientific papers; in order to facilitate the subsequent publication of the parts as well. The first part deals with the extrapolation of species richness to the entire area of the Observatories based on a specially sampled data set, the second compares the studied Observatories in terms of biotic and abiotic characteristics, and the third part discusses the completeness of vegetation surveys of large areas. This 'cumulative' thesis receives a common framework by a general section that contains general contents, such as the description of the study area or of the vegetation sampling methology. 


\section{Contents}

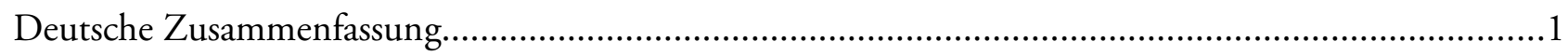

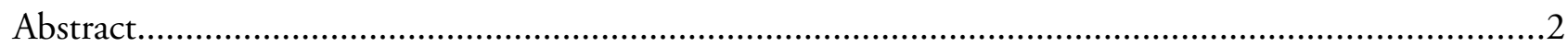

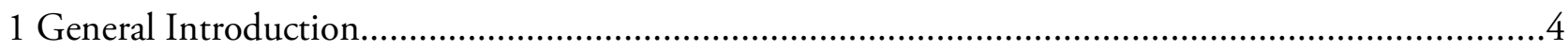

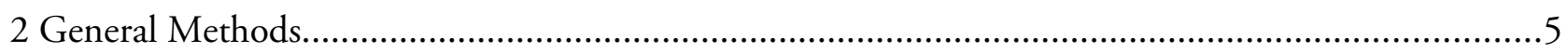

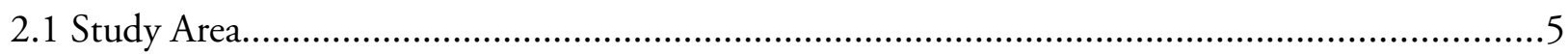

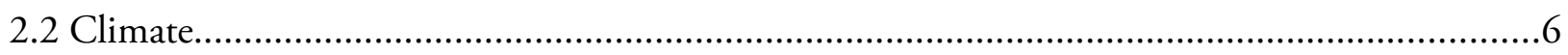

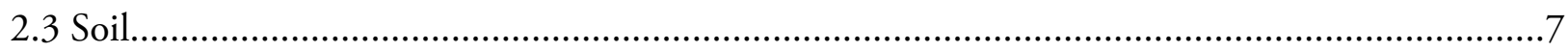

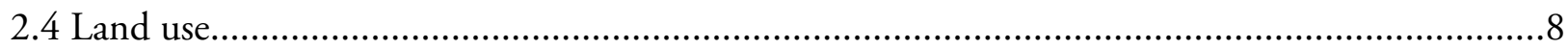

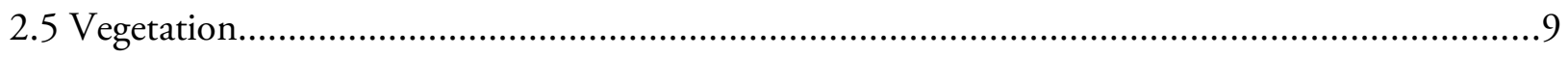

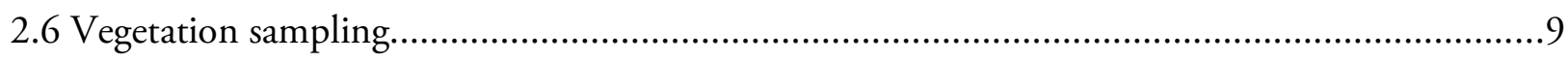

3 Evaluating different approaches to estimate plant species richness at the

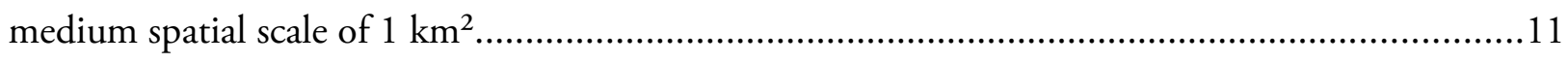

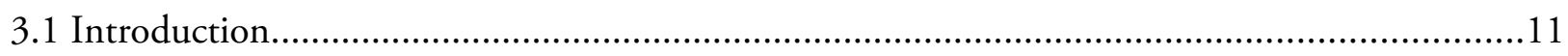

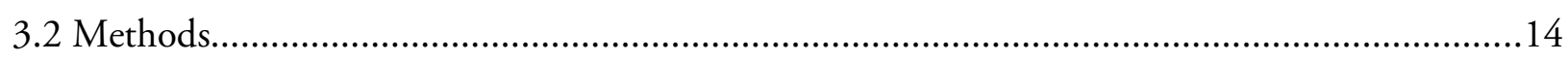

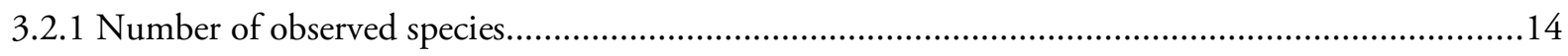

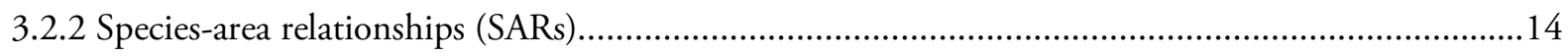

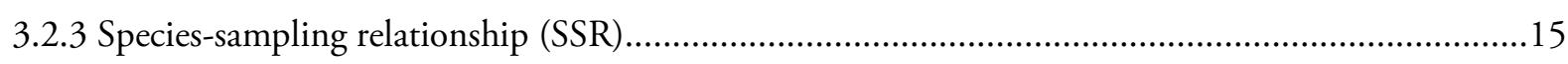

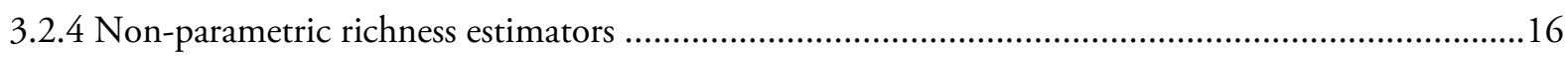

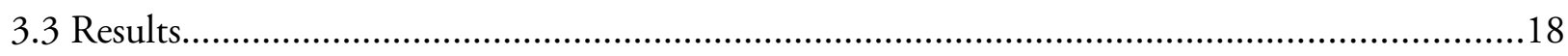

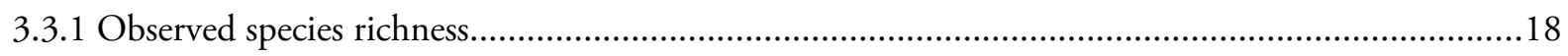

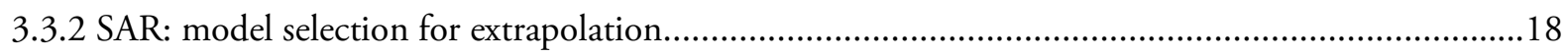

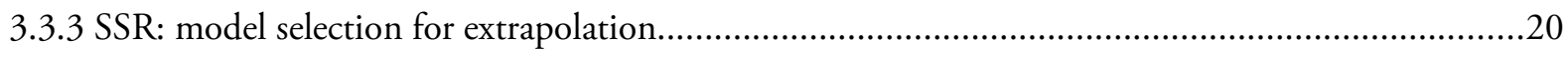

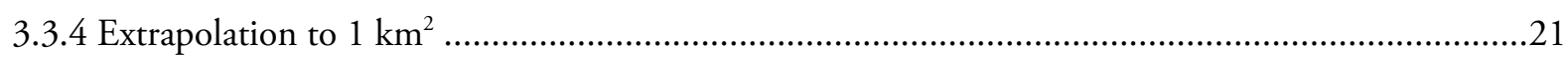

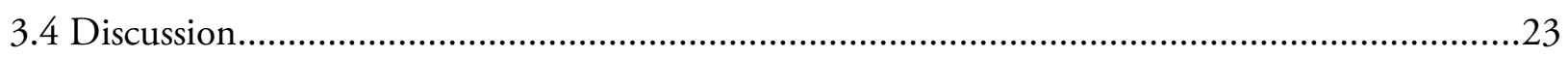

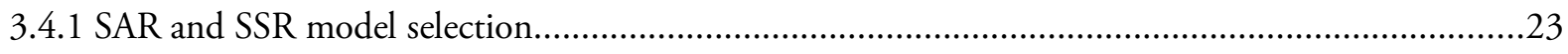




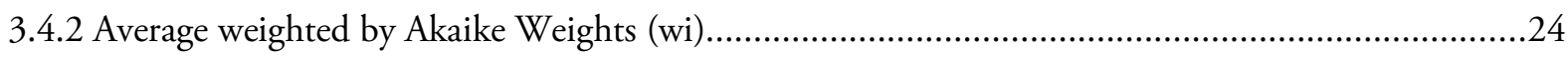

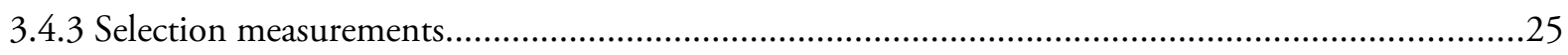

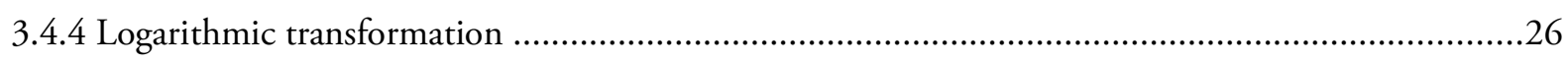

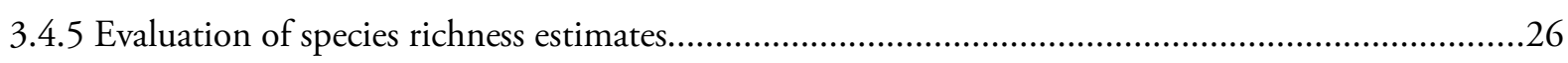

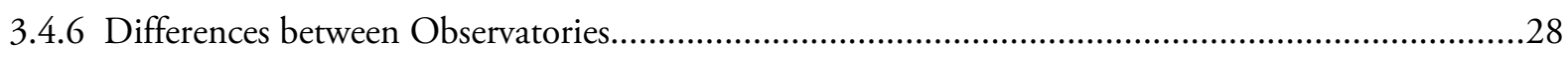

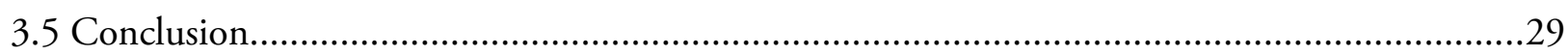

4 How does differing grazing intensities influence plant diversity patterns at various spatial scales?

Comparison of the BIOTA-Observatories Narais and Duruchaus in central Namibia...................31

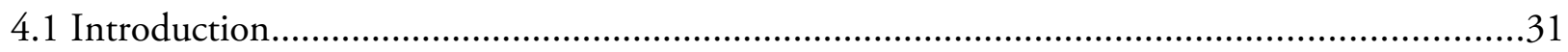

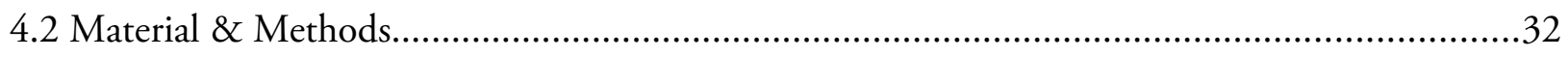

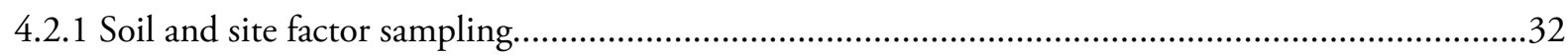

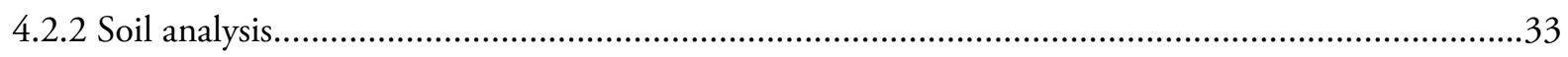

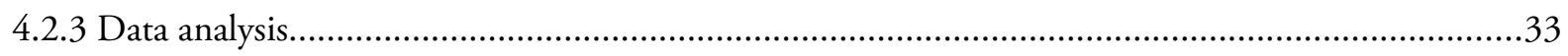

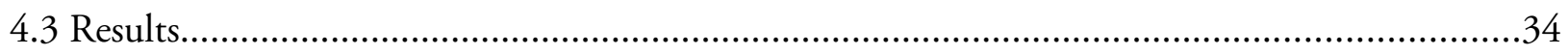

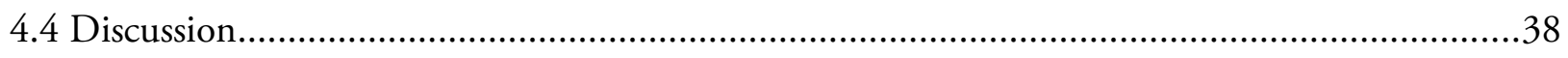

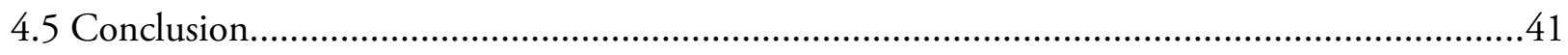

5 Effects of sampling time effort on completeness of vegetation surveys in a semi-arid savanna

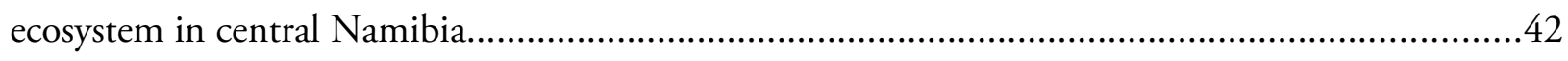

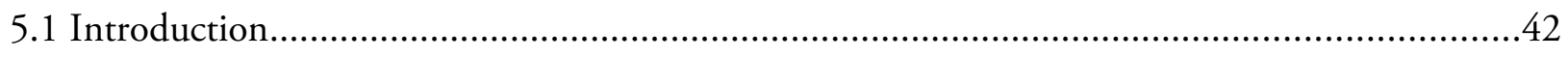

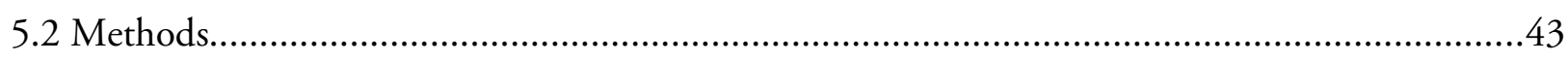

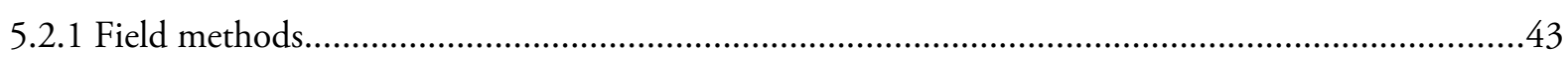

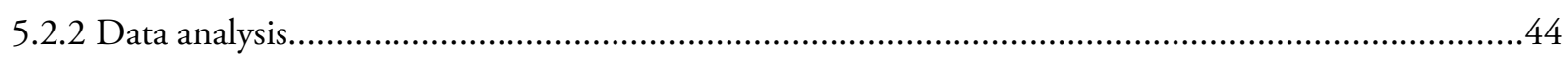

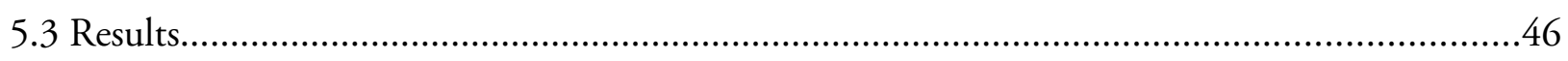

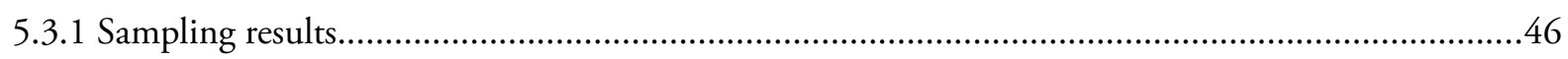

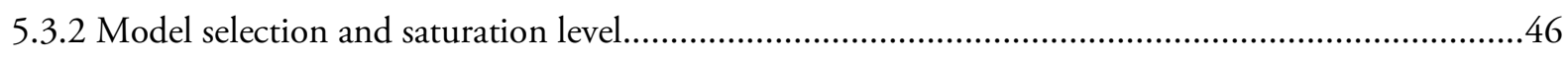

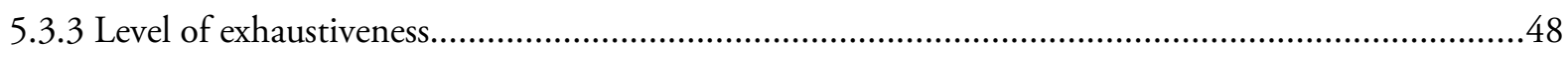

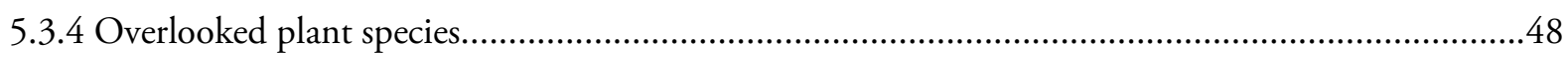




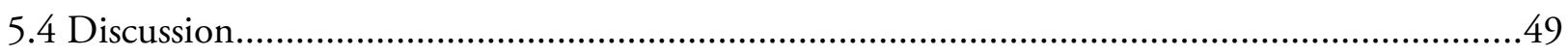

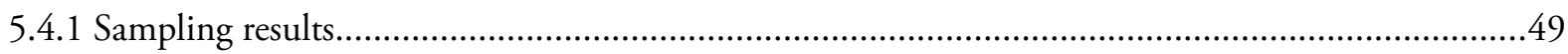

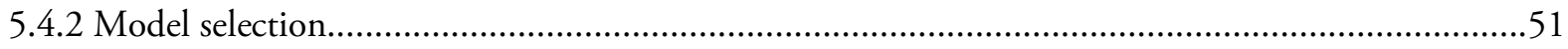

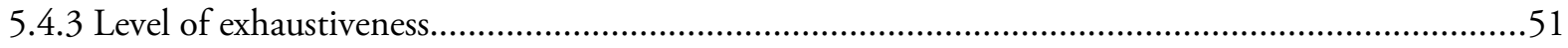

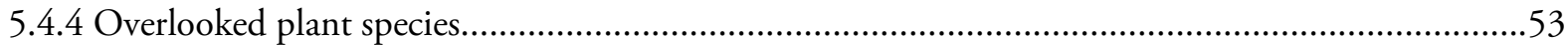

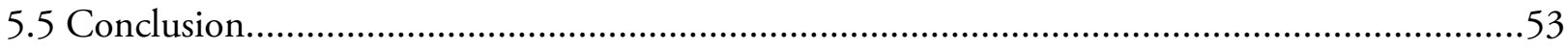

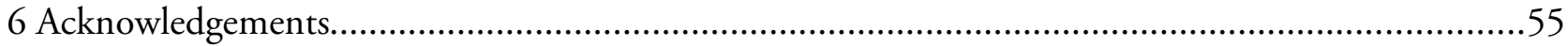

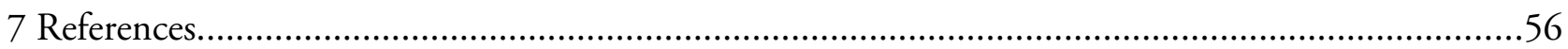

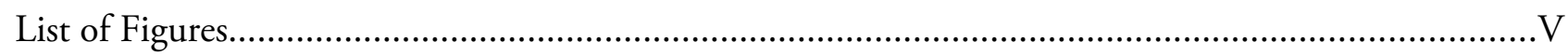

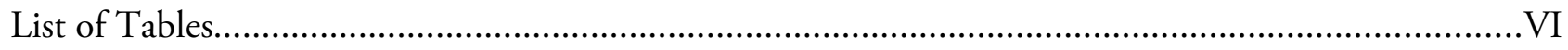

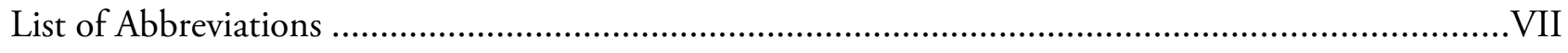

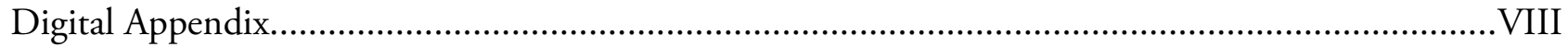

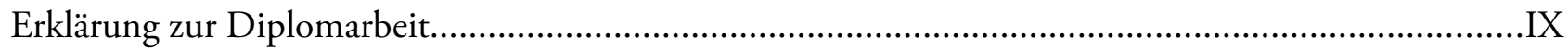




\section{Deutsche Zusammenfassung}

Die vorliegende Studie wurde auf dem BIOTA-Observatorienpaar Narais und Duruchaus in einem semi-ariden Savannenökosystem in Zentralnamibia durchgeführt. Die beiden Observatorien wurden aufgrund der sie unterscheidenden Landnutzungsintensität ausgewählt, die durch einen starken Zaunkontrast gekennzeichnet ist. Die Duruchaus Farm wird mit hoher Intensität mit Rindern und Schafen beweidet, die Narais Farm dagegen ist nur schwach beweidet. Die drei Hauptziele dieser Arbeit waren i) die Unterschiede zwischen den Observatorien hinsichtlich Vegetationszusammensetzung, Pflanzendiversität und Standortfaktoren auf unterschiedlichen Skalenebenen herauszufinden und vor dem Hintergrund unterschiedlicher Beweidungsintensitäten zu bewerten, ii) Schätzungen für die Gesamtartenvielfalt jedes der Observatorien abzugeben unter der Anwendung und im Vergleich dreier verschiedener Extrapolationsmethoden, die gewöhnlich in der Biodiversitätsforschung Verwendung finden (Art-Areal-Beziehung $=$ SAR, Art-Stichproben-Beziehung $=$ SSR, sowie nicht-parametrische Vielfaltschätzverfahren) und iii) den Einfluss des Zeitaufwands auf den Grad der Vollständigkeit von floristischen Bestandsaufnahmen auf dem Maßstab von einem Hektar zu testen.

Während der Regenzeit 2009, wurden auf jeweils 20 vollständig randomisiert verteilten Aufnahmeflächen pro Observatorium von $1000 \mathrm{~m}^{2}$ Größe alle Gefäßpflanzenarten aufgenommen. In jede Aufnahmefläche wurden Unterflächen von $0,01 \mathrm{~m}^{2}, 0,1 \mathrm{~m}^{2}, 1 \mathrm{~m}^{2}, 10 \mathrm{~m}^{2}$ und $100 \mathrm{~m}^{2}$ geschachtelt und repliziert. Auf allen $100-\mathrm{m}^{2}$ Unterflächen wurden Bodenproben entnommen und analysiert. Zusätzlich wurden zehn 1-ha Aufnahmeflächen mit einem standardisierten Verfahren mit hohem Zeitaufwand aufgenommen, wobei die Zeitpunkte beim Erfassen einer neuen Art festgehalten wurden.

Um potentielle Unterschiede der Durchschnittswerte der Parameter zwischen den Observatorien zu analysieren, wurde ein Permutationstest angewendet. Die Art-Areal-Beziehungen wurden mit 12 verschiedenen Modellen (Potenzfunktion, logarithmische Funktion und asymptotische Funktionen) modelliert, die Art-Stichproben-Beziehungen mit sechs asymptotischen Modellen. Des Weiteren wurden vier nicht-parametrische Artenvielfaltschätzverfahren angewandt. Die Kurven der Arterfassung gegen die Aufnahmezeit auf den 1-ha Aufnahmeflächen wurden mit der gleichen Zusammenstellung an sechs asymptotischen Funktionen wie die Art-Stichproben 
Beziehungen modelliert, um die tatsächliche Artenvielfalt auf den jeweiligen Hektarflächen zu bestimmen. Schließlich wurden die Artenlisten der Hektarflächen mit denen aus dem BIOTAStandardaufnahmeverfahren aus demselben Jahr und kumuliert über fünf Jahre verglichen.

Im Ergebnis gab es i) kaum einen Unterschied in der Artenvielfalt zwischen den unterschiedlich stark beweideten Observatorien auf unterschiedlichen Skalenebenen, wohingegen andere Biodiversitätsindikatoren und die Artenzusammensetzung stark abwichen. ii) Der Ansatz, mit Extrapolation der Art-Areal-Beziehungen als Potenz- oder quadratischen Potenzfunktionen die Gesamtartenzahl auf Observatorienmaßstab $\left(1 \mathrm{~km}^{2}\right)$ zu bestimmen, lieferte die besten Ergebnisse, während die andere Methoden die Gesamtartenzahl substanziell unterschätzten. iii) Die Anwendung der modellierten Arten-Zeitaufwandskurven der Hektarflächen stellte sich als geeignet heraus, die Gesamtartenvielfalt dieser Flächen zu schätzen und Informationen zur Vollständigkeit von Vegetationsaufnahmen zu liefern. Die in den BIOTA-Standardaufnahmen übersehenen Arten waren größtenteils selten, kleinwüchsig oder gehörten zur Gruppe der annuellen Kräuter und Gräser.

\footnotetext{
Abstract

This study was performed on the BIOTA Observatories pair Narais and Duruchaus in a semiarid savanna ecosystem in central Namibia. The two Observatories have been chosen because of their different land-use intensities which is indicated by a strong fence line contrast. The farm of Duruchaus is grazed with high intensity by cattle and sheep, whereas the Narais farm is only lightly grazed.

The study had three major goals: i) to identify differences between the Observatories at different spatial scales regarding plant diversity, vegetation composition, and site conditions and to evaluate them with respect to the differing grazing intensities; ii) to give an estimate of the total plant species richness of each Observatory by applying and comparing three different extrapolation methods commonly used in biodiversity research (species-area relationships = SARs; species-sampling relationships = SSRs; non-parametric richness estimators); and iii) to test the influence of time effort on the degree of completeness of floristic inventories at the 1-ha scale. During the rainy season of 2009, all vascular plants were sampled on 20 completely randomly distributed $1000-\mathrm{m}^{2}$ plots on both Observatories. Within each plot, subplots of $0.01 \mathrm{~m}^{2}, 0.1 \mathrm{~m}^{2}$,
} 
$1 \mathrm{~m}^{2}, 10 \mathrm{~m}^{2}$, and $100 \mathrm{~m}^{2}$ were nested and replicated. Soil samples were taken and analysed from all $100-\mathrm{m}^{2}$ subplots. Additionally, ten 1-ha plots were sampled in a standardised way with high time effort, registering the point of time, whenever a new species was encountered.

A permutation test was used to analyse potential differences in parameter means between the Observatories. SARs were fitted by 12 different models (power, logarithm, asymptotic) and SSRs by six asymptotic models. Further, four non-parametric richness estimators were applied. The curves of species encounters versus sampling time of the 1-ha plots were fitted with the same set of six asymptotic functions as the SSRs in order to determine the 'true' richness within a specific hectare plot. Finally, the species lists for hectare plots were compared to those gained with BIOTA 'standard' sampling in the same year and accumulated over five years.

As results, i) there was hardly any difference between the differently grazed Observatories in species richness at the different spatial scales, while other biodiversity indicators and species composition strongly deviated. (ii) The SAR approach with power or quadratic power functions worked best for extrapolation to the Observatory scale $\left(1 \mathrm{~km}^{2}\right)$, while other methods substantially underestimated the total species richness. (iii) The species-time approach proved to be an appropriate tool to specify the total species richness of the distinct area of 1 ha and to provide information on the completeness of vegetation censuses at this scale. Species overlooked during BIOTA 'standard' sampling were mostly rare, low-growing, and/or belong to the group of annual forbs or graminoids. 


\section{General Introduction}

Public awareness of biodiversity loss has risen rapidly since the implementation of the Convention on Biological Diversity (CBD) (UNEP, 1992) on the United Nations Conference on Environment and Development, which was held in Rio de Janeiro in 1992. The member states are obliged to establish effective biodiversity conservation plans, sustainable use strategies (CBDArticle 6), and programs to monitor biodiversity (CBD-Article 7). Therefore, politicians and decision makers from all over the world ask for detailed information on biodiversity indicators like species richness (BALMFORD et al., 2005). Species richness describes one part of the broader term 'biodiversity' which also includes genetic diversity, diversity of biological communities, landscapes and ecosystems (GASTON \& SPICER, 2006). Nevertheless, time, financial, and personnel resources are still limited in ecological and biodiversity research, so only poor data on species richness distribution exists in most regions on earth, especially in the tropics and deep-sea ecosystems (Magurran, 2004). To fill these gaps in a conceivable time span, scientifically proven methodology is needed to give justified richness values with low sampling effort and costs (MAY, 1988; Gaston, 2000; Gotelli \& Colwell, 2001).

In vegetation ecology, different approaches for sampling (SHMIDA, 1984; Dengler, 2009a) and monitoring (PEET et al, 1998; JÜRGENs et al., submitted) plant diversity have been developed to fulfil these requirements. These field methods are supplemented by essential techniques to estimate species richness on larger scales than sampled (Colwell \& Coddington, 1994; Magurran, 2004; Dengler, 2009b). However, the adequacy of the methodology to give reasonable estimates for species richness as an indicator for biodiversity has rarely been tested in the scientific literature, despite several reported shortcomings and pitfalls (Gotelli \& Colwell, 2001; Dengler, 2008, Dengler, 2009b). Furthermore, most of the methods have been used only in well studied regions like Europe, North America, or some biodiversity hotspots (FRIDLEY et al., 2005; Chazdon et al., 1998; Dengler \& Boch, 2008), but rarely in other ecosystems as savannas in southern Africa. In this region, severe concerns about biodiversity loss because of land use and climate change occur (JürGENS et al., 2010a).

Another field of interest is the effect of spatial heterogeneity at different scales on species richness patterns, which is not fully understood yet (Huston, 1999). Environmental and anthropogenic 
factors play an essential role in the distribution of plant species and communities. In rangeland ecosystems, the influence of grazing intensity on vegetation and plant diversity is of special concern (Olff \& Ritchie, 1998). Most studies deal with spatial heterogeneity at meso- or macro scales (Nichols, 1998; Dufour, 2006) and there is a lack of information on smaller plot scales which were surveyed in this study.

This study was associated to the BIOTA ( $\underline{B i o d i v e r s i t y ~ M o n i t o r i n g ~ T r a n s e c t ~} \underline{\text { Analysis in Africa) }}$ regional sub-project in Southern Africa (JÜRGENS et al., 2010a) which tried to fill the lack of interdisciplinary knowledge on biodiversity in the southern African region with the help of Biodiversity Observatories (in the following text referred to as Observatories) (JüRGENS et al., submitted). On two neighbouring Observatories in central Namibia, an additional sampling protocol was applied and analysed to get further insights in sampling procedures of plant diversity. The two Observatories provide excellent conditions to investigate the influence of grazing intensity because they show similar ecological characteristics but differ strongly in livestock management (HAARMEYER et al., 2010).

The main targets of this study were i) to give reliable species richness values for two exemplary sites of $1 \mathrm{~km}^{2}$ each in a semi-arid savanna ecosystem in central Namibia by employing the standardised, multi-scale sampling method of Dengler (2009a) and evaluating different approaches of species richness estimation, ii) to identify the differences in plant diversity patterns at different spatial scales on the two Observatories characterized by different grazing intensities, and iii) to test the influence of sampling effort at the 1-ha plot scale by comparing the results of different sampling and estimating procedures.

\section{General Methods}

\subsection{Study Area}

I carried out this study on the two BIOTA Biodiversity Observatories Narais (north-west-corner: $23^{\circ} 7.2492^{\prime} \mathrm{S}, 16^{\circ} 53.8237^{\prime} \mathrm{E}$ ) and Duruchaus (north-west-corner: 23⒏0168' S, 1654.029' E) (Figure 2-1). The BIOTA biodiversity monitoring program established biodiversity Observatories $\left(1,000,000 \mathrm{~m}^{2}\right.$ size $)$ arranged in transects following climatic gradients in the southern African region. One part of the interdisciplinary project is the standardised long-term monitoring of 
vascular plants at selected hectare plots of the Observatories (Jürgens et al., submitted). The two Observatories Narais and Duruchaus were established in 2004. They are situated in the central Namibian Khomas region (about $30 \mathrm{~km}$ north-west of the town Rehoboth). The areas of the Observatories are located in adjacent parts of two neighbouring farms which are separated by a fence line (HAARMEYer et al, 2010).

The study area at the altitude of $1600 \mathrm{~m}$ a.s.l. is characterized by a mainly flat and homogeneous plain which is dissected by some drain gullies on the Duruchaus Observatory and pan structures on the Narais Observatory, respectively.

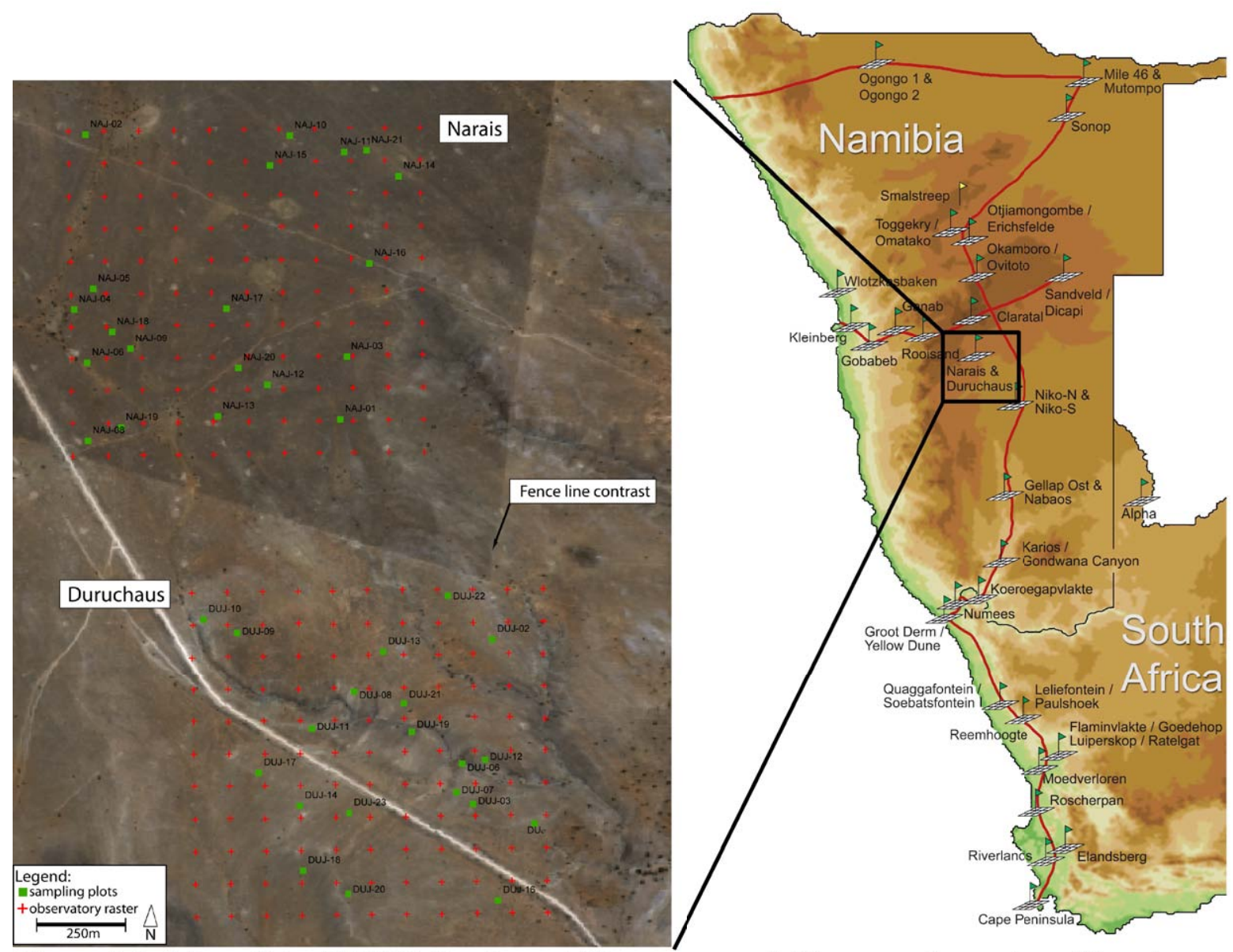

Figure 2-1: Map of the BIOTA Southern Africa transect of Observatories and satellite picture of BIOTA Observatories Narais and Duruchaus with sampling plots of this study (green squares) and highlighted fence line contrast. (sources: BIOTA Africa, Hymap Satellite Picture 2005, edited).

\subsection{Climate}

The semi-arid climate of central Namibia is characterized by a hot rainy season in summertime (December-April) and dry winters (May-November) (Figure 2-2). The mean annual temperature 
of the study site is $19.1^{\circ} \mathrm{C}$ (HaArmeyer et al, 2010). Maximum daily temperatures around $35^{\circ} \mathrm{C}$ may occur during the rainy season, minimum of $-2{ }^{\circ} \mathrm{C}$ in the winter. The average annual precipitation amounts to $289 \mathrm{~mm}$, occurring mainly as highly sporadic and local thunderstorms. Highest precipitation is measured from January till March with a high spatial and temporal variability (maximal $271 \mathrm{~mm}$ monthly) (HAARMEYER et al, 2010). Because of the high evapotranspiration rate, a water deficit of 2100-2300 mm per year occurs (MENDELSON et al., 2009). In the rainy season $2008 / 09$, when I conducted the field work for this study, precipitation was quite evenly distributed over the season and amounted to $542 \mathrm{~mm}$ (data from Duruchaus farmhouse; D. Wesuls, personal communication, 2010) - $250 \mathrm{~mm}$ more than the long-term average. Thus, the water availability provided proper growth conditions for plant life in the year of this study.

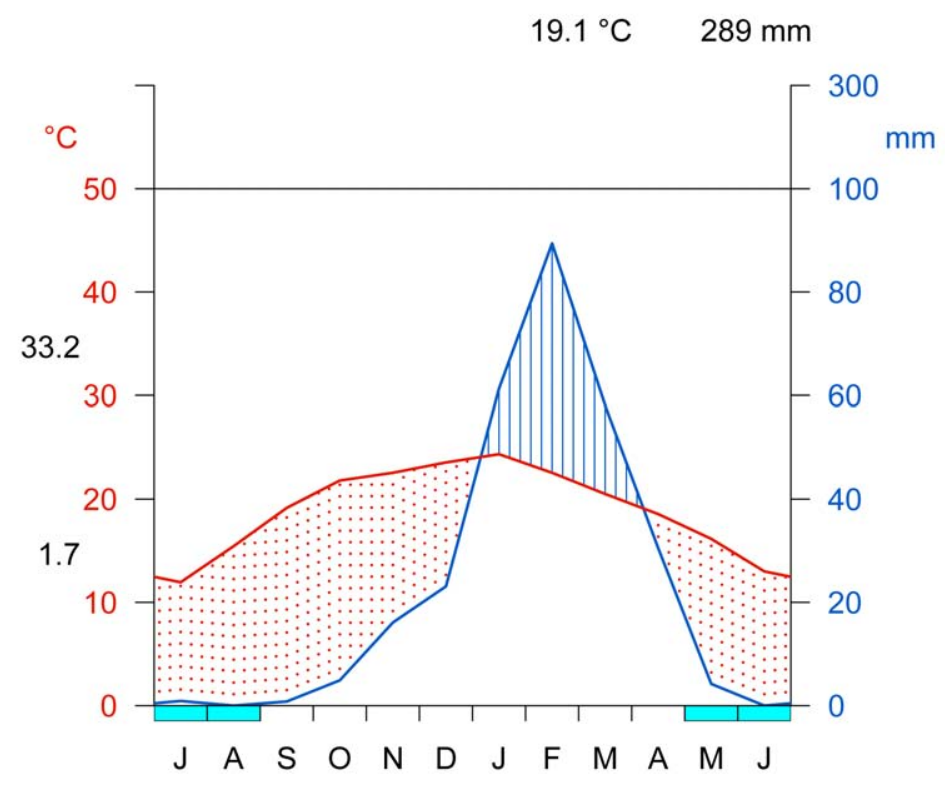

Figure 2-2: Climate diagram of the BIOTA Observatory Narais, central Namibia (source: HAARMEYer et al., 2010; data: 2004-2009).

\subsection{Soil}

The bedrock of the study site is formed by mica schist and calcareous schist of the geological Nosib group (Damara Sequence) (Petersen, 2008). Only thin soil layers of various types exist. It consists mostly of Calcisols but also unevenly distributed Leptosols, Regosols and Luvisols can be found (HaArmeyer et al., 2010). The pH-values range between neutral to slightly alkaline, the electrical conductivity is generally low. These soil chemical properties show very low variability on both Observatories. The horizontal variation of organic carbon, texture, and the rooted space is 
more prominent (PETERSEN, 2008). The soil layer is narrowed by a massive calcrete crust which is impermeable for many deep rooting plants and thus limits their growth and abundance.

As a special feature, well developed biological soil crusts (BSCs) built up by cyanobacteria, green algae, and lichens can be found on both Observatories and give the soil surface a dark colour which increases the soil temperature due to the absorption of sun radiation (HAARMEYER et al, 2010).

\subsection{Land use}

The farm of Duruchaus, with 4093 ha considerably smaller than the neighbouring farm Narais with 8762 ha, is highly grazed by cattle, sheep and goats with an average stocking rate of between

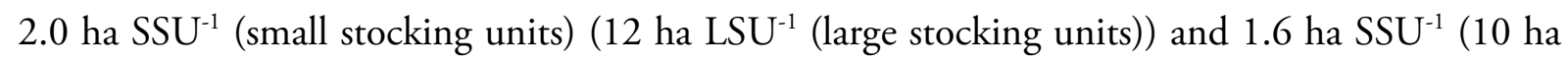
$\mathrm{LSU}^{-1}$ ). On Narais only low grazing by cattle, goats, and game with an average stocking rate

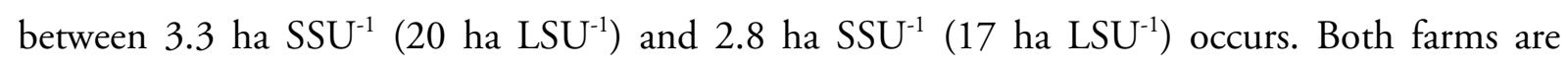
subdivided into different camps for grazing rotation management (HAARMEYER et al, 2010). The camp including the Observatory on Narais farm was only grazed by wild game in the month before and during the field work for this study. The two farms are separated by a fence and thereby a strong grazing gradient has developed since the 1980s (HAARMEYER et al, 2010) (Figure 2-3). The fence line contrast is characterized by a different distribution and abundance of plant species and BSCs.

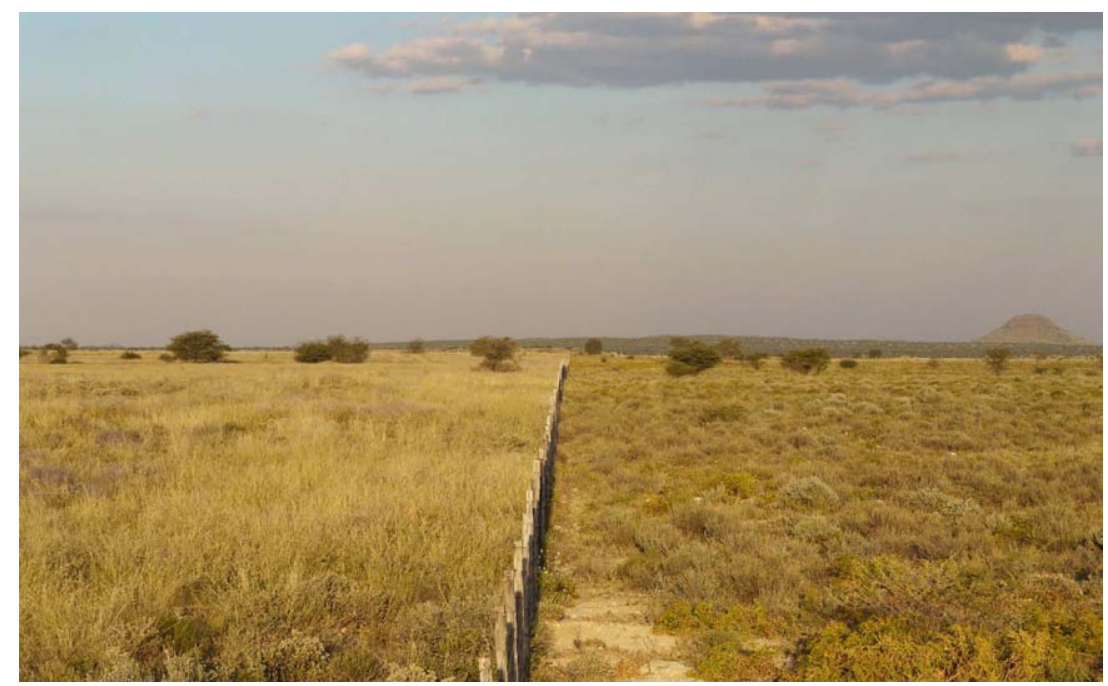

Figure 2-3: Fence line contrast separating the Observatories Narais (on the left) and Duruchaus (on the right) (photo D. Wesuls, 2009). 


\subsection{Vegetation}

The study site lies at the transition zone between three vegetation zones: the Nama Karoo to the south, the Namibian tree and shrub savannah to the north, and the Kalahari shrubland to the east (Mendelson et al., 2009). The climate conditions refer more to the thorn shrub savannah $(-400$ mm precipitation) (Palmer \& Hoffman, 1997) but due to edaphic factors (chalk crust, see chapter 2.3) a lot of floristic elements of the Nama Karoo association like dwarf shrub and grass species are found in the area (HAARMEYER et al, 2010).

Following the BIOTA vegetation classification, Narais Observatory is dominated by the Stipagrostis ciliata-Eriocephalus luederitzianus community which is characterized by perennial grasses such as Stipagrostis ciliata and Stipagrostis obtusa mixed with the dwarf shrub species Eriocephalus luederitzianus and Leucosphaera bainesii. On hydrologically favoured sites in pans, called vleis in locally spoken Afrikaans, or drainage lines communities dominated by other grass species like the Cyphostemma hereroense-Panicum lanipes community occur (HAARMEYER et al, 2010)

On Duruchaus Observatory, the vegetation is mainly built up of Stipagrostis obtusa-Limeum aethiopicum community consisting of the small growing perennial grass Stipagrostis obtusa, the dwarf shrubs Limeum aethiopicum, and grazing tolerant herbal species like Aptosimum albomarginatum, Pteronia mucronata, or Monechma genistifolium. This community is stated to be a slightly degraded form of the Stipagrostis ciliata-Eriocephalus luederitzianus community on Narais due to stronger grazing impact (HAARMEYER et al, 2010). In the drainage lines, other communities with a higher proportion of woody species like the Heteropogon contortus-Ziziphus mucronata community grow. Larger shrubs and trees (Acacia sp.) occur only sparsely at edaphically favoured sites on both Observatories (HAARMEYER et al, 2010).

\subsection{Vegetation sampling}

I distributed 20 completely randomized vegetation plots on both Observatories and localised them with the help of a handheld GPS device (Garmin GPS 60) in the field, taking the coordinate given by the randomization process as the north-west edge of the plot. Each of these 40 plots covers $1,000 \mathrm{~m}^{2}$ in a quadratic form $(31.62 \mathrm{~m} \mathrm{x} 31.62 \mathrm{~m})$. Inside these plots $0.01,0.1$, 1,10 and $100-\mathrm{m}^{2}$ quadratic subplots were nested. All subplots were replicated three times, placed 
in the north-western and south-eastern corners and in the middle of the $1,000-\mathrm{m}^{2}$ plot (Figure 24, Dengler 2009a). I recorded all vascular plant species applying the any-part-system (Dengler 2009a) what means that every species with any living part of an individual present in the plot was recorded. The sampling started from the smallest subplot and proceeded stepwise to the largest scale. The plant taxonomy follows Craven (1999). On each $100-\mathrm{m}^{2}$ subplot, total and species cover was estimated on a percent scale using stepped intervals $(0.1 \%, 0.5 \%, 1 \%, 2 \%$, continued in $1 \%$ steps). The field work took place in March 2009. At the end of the rainy season, most of the vascular plant species were fully developed and could easily be found and identified. All vegetation data were stored using the vegetation database software BIOTAbase (Muche et al., 2010b).

\section{a)}

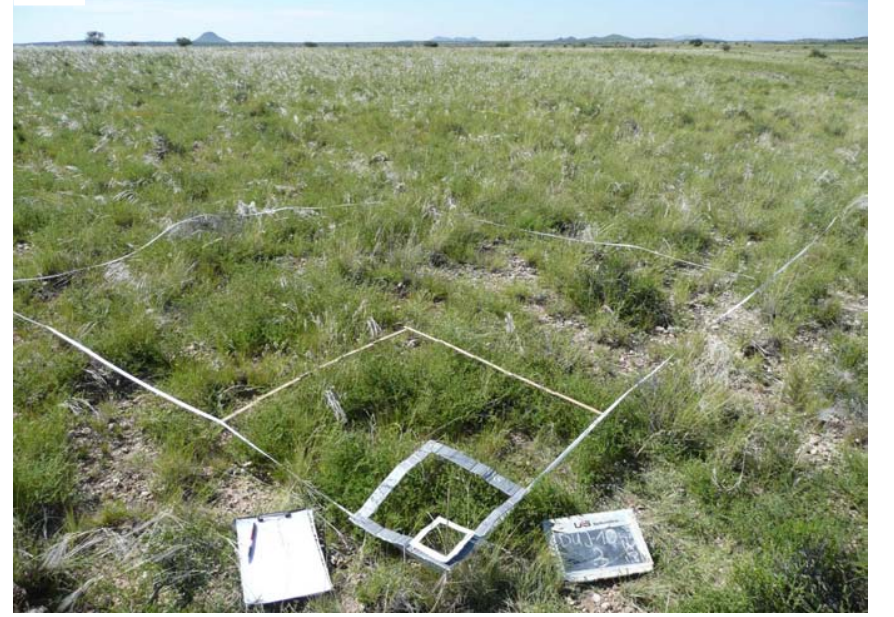

b)

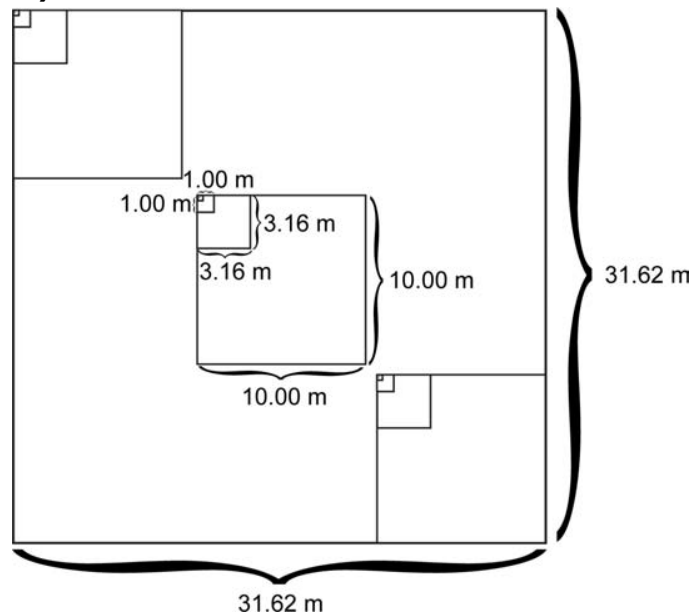

Figure 2-4: a) Landscape impression of the study area (Observatory Duruchaus), b) Vegetation sampling design. Threefold replicated nested plot design. $0.01-$ and $0.1-\mathrm{m}^{2}$ scales are not shown. 


\section{Evaluating different approaches to estimate plant species richness at the medium spatial scale of $1 \mathrm{~km}^{2}$}

\subsection{Introduction}

In many ecological studies, species richness is taken as a measure for biological diversity of the studied site and ecosystem (Colwell \& Coddington, 1994; Chiarrucci et al., 2003; Wei et al., 2010). However, it is extremely challenging to achieve reliable richness values for larger areas by sampling, especially of small or mobile taxa like bacteria, fungi, or animals. For vascular plants as sessile taxa, comprehensive species sampling designs have been developed for small scales (a few $\mathrm{cm}^{2}$ to $1,000 \mathrm{~m}^{2}$ ) in the last decades (Westhoff \& van der Manel, 1978; Shmida, 1984; Dengler, 2009a). Also suitable methods to determine species richness of large scales have been established if sufficient species inventories exist for the concerned region and taxon (GASTON, 2000; KiER et al., 2005). For nature conservation and land use decisions, it is of special interest to gain also good knowledge about species richness for different zoological and botanical taxonomic groups at an intermediate scale ranging between $1,000 \mathrm{~m}^{2}$ and $100 \mathrm{~km}^{2}$ (GASTON, 1996; Chiarruci \& Palmer, 2006; Smith, 2010). Complete sampling of such an area is impossible because the effort to find very rare or hidden species is unaccomplishable with human and financial resources or would actually destroy the biota of the sampled site (PALMER, 1995; GASTON, 1996). Therefore, numerous approaches to estimate species richness of distinct areas and all kinds of taxonomic groups have been established and applied in biodiversity studies since years (CHAO, 1984, 1987; Colwell \& Coddington, 1994; Magurran, 2004). However, there is still a discussion in the scientific community which approach should be applied to meet the main targets of a good estimator. It should provide values close to actual numbers or at least over- or underestimate consistently to a well-known magnitude (PALMER, 1990). Six types of estimators have been proposed: (1) number of actually sampled species, (2) extrapolation of the species-area relationship (SAR) (Palmer, 1990; Dengler, 2009; Dengler \& Oldeland, 2010), (3) extrapolation of the species-sampling relationship (SSR) (STOUT \& VANDERMEer, 1975; DengleR \& Oldeland, 2010), (4) so called 'non-parametric estimators' (Chao, 1984; MagGuran, 2004), (5) the integration of log-normal distribution (Preston, 1948; Cohen, 1959), and (6) the new 
approach of upscaling with an universal species-area curve (HARTE et al., 2009). Several studies evaluated the output of a subset of these estimators to simulated (CHIARUCCI et al., 2003; Dengler \& Oldeland, 2010) or to empirical data (Palmer, 1990; Stiles \& Scheiner, 2007; Wei et al., 2010) but the results of these studies are hardly comparable since divergent estimators, data sampling methodologies, and typologies were used, all of which strongly influence the performance of the estimators (DENGLER, 2009b).

The typology and application of species-richness relationships as SARs and SSRs has recently been discussed controversially in the literature by several authors (SCHEINER, 2003, 2009; Gray et al., 2004; Dengler, 2009b; Dengler \& Oldeland, 2010). Dengler (2009b) emphasised the fundamental theoretical and practical difference in curve shape and extrapolation abilities between SAR and SSRs models. He argued that SARs should be constructed only from data of contiguous area (nested or non-nested) and have no upper asymptotes whereas SSRs refer to scattered samples (individuals, plots) within a defined larger area, of which they can give the total species richness by an asymptotic saturation of the curve. For model selection, he proposed a combined use of an information criterion approach (AKAIKE, 1978; BURNHAM \& ANDERSON, 2004) instead of the often used $R_{\text {adj }}^{2}$ (e.g. Flather, 1996; Thompson et al., 2003), and the newly developed Logarithmic Error of Extrapolation (LEE) as a special measure for extrapolation capability of a model (Dengler, 2009b). Additionally, he stated extrapolations from SARs to be more reliable than from SSRs. SCHEINER $(2003,2009)$ refused the strict differentiation between SARs and SSRs and favoured SSR models for extrapolation. Furthermore, it is unclear which of the several proposed and applied functions are most accurate to describe the shape of SAR and SSR properly (Williams, 1995; Flather, 1996; Lomolino, 2002; Tjørve, 2003; Dengler, 2009b), and if there is only one generally valid function fitting data from all ecosystems and taxonomic groups. Thus, several authors proposed to adequately test a set of alternative functions to fit the SAR with appropriate measurements in each ecological study (SCHEInER, 2003; TJøRve, 2003; Dengler, 2009b).

In this study, I applied both concepts of SARs and SSRs for field data by calculating asymptotic and non-asymptotic functions to fit the SAR and asymptotic ones to fit the SSRs. I evaluated them by their goodness-of-fit and tested their extrapolation capability. To complete this broad 
comparison of different estimator types, I used a set of non-parametric richness estimators as well. I did not use log-normal distribution models because they were not widely applied and had turned out to be inappropriate to give reasonable results in previous studies (PALmER, 1990; Walther \& MoOre, 2005). The upscaling procedure with an universal species-area curve after HARTE et al. (2009) with its huge theoretical background of the maximum entropy principle and mathematical equations would go far beyond the scope of this diploma thesis and therefore it was left open here.

I adopted all these methods to a field data set of a standardised vegetation sampling scheme in a semi-arid savanna in central Namibia (see chapters 2.1. and 2.6.). The two studied BIOTA Observatories (covering $1 \mathrm{~km}^{2}$ each) differ mainly in grazing intensity (see chapter 2.4.) and were analysed separately to allow a comparison of the output of the estimation methods under different ecological conditions.

The major objectives of this study were i) to assess the goodness-of-fit and extrapolation capability of the applied SAR and SSR models, ii) to evaluate the performance of diverse species richness estimation methods with the help of field data, iii) and finally to provide reliable estimates for total species richness for each of the two Observatories. 


\subsection{Methods}

To extrapolate species richness to the size of the whole Observatories (see chapter 2.1. for study site description), I applied three methods commonly used in biodiversity research and ecology (Dengler \& Oldeland., 2010) and compared their outputs.

\subsubsection{Number of observed species}

I entered all sampled species-specific data into a BIOTAbase database (Muche et al., 2010a) and determined the mean and total species richness and the constancy of plant species for each sampled scale on the whole study site and for the two Observatories separately. My total species list of each Observatory, I merged with the accumulated species list from the BIOTA monitoring scheme (D. Wesuls, unpublished data, 2010) in order to get a better idea of the total species richness on the Observatories to which I could compare the resulting estimates. A complete census of all occurring plant species does not exist for the Observatories. The BIOTA monitoring scheme was performed on the same two Observatories but with a deviating sampling design and on other specific plot locations (JÜRGENS et al., submitted). I used the data from 2005 till 2009, which was sampled during the rainy seasons i.e. the months February-April of the years concerned.

\subsubsection{Species-area relationships (SARs)}

Within each main plot $\left(1,000 \mathrm{~m}^{2}\right)$, I calculated the mean species richness of all sub-plots of the same scale and fitted 12 different functions to this data in order to describe the resulting speciesarea relationships (SARs). I applied the linear [1], power [2], quadratic power [3], power (Plotkin, approximate) [4], logarithmic [5], quadratic logarithmic [6], Michaelis-Menten (Monod) [7], negative exponential [8], rational [9], logistic [10], Lomolino [11], and asymptotic regression function [12] (overview and review in Dengler, 2009b, Table 3-1). For model fitting, I used the non-linear least-square method (function 'nls' in R (R Development Core Team, 2008)).

For model selection, I determined the AICc (Akaike Information Criterion, corrected for small $n$ ) with the maximum likelihood $(L(\theta / y))$ method for each model. I calculated the $\triangle \mathrm{AICc}$ scores by subtracting the lowest AICc of all models from the AICc of the considered model (Burnham \& Anderson, 2004). Burnham \& Anderson (2004) proposed to use the AICc instead of the original 
AIC not only for small samples because AICc converges to AIC if $n$ gets large. In order to weight the different models for further analysis after their fitting capability, I also calculated the Akaike Weights $\left(w_{i}\right)$ for the models (Burnham \& Anderson, 2004). Additionally, I calculated the Logarithmic Error of Extrapolation (LEE) after Dengler (2009a) for each model. For this purpose, I omitted all data larger than one-tenth of the largest area (in this study all larger than $100 \mathrm{~m}^{2}$ ) and fitted the same SAR models (Table 3-1) with the same method as before (function 'nls' in R (R Development Core Team, 2008)) to this reduced data set. Then I calculated the estimated species richness for the $1,000-\mathrm{m}^{2}$ scale with the resulting model parameters and compared them with the actually observed species richness for this scale. I described the deviation by the difference of predicted and observed richness on a $\log S$-scale.

Finally, I averaged the $\triangle$ AICc and LEE values for every model and Observatory and ranked them in descending order. I determined an average total rank of both goodness-of-fit metrics.

With the best-fitting functions (power, power quadratic, logarithmic quadratic, and Lomolino function) I scaled up to the species richness of $1 \mathrm{~km}^{2}\left(1,000,000 \mathrm{~m}^{2}\right)$ with the individual model formula and parameters of every single plot and afterwards averaged the numbers for each model and Observatory. I determined the standard error of the mean (SE) as a measurement for the estimation precision. In addition, I computed an average extrapolated species richness with the data of all plots and tested models weighted by the Akaike Weights $\left(w_{i}\right)$. Thus, the potential capability of each model to fit the data influenced this extrapolation estimate.

\subsubsection{Species-sampling relationship (SSR)}

To describe the species-sampling relationships (SSRs), I calculated sample-based or so called species accumulation curves (Gotelli \& Colwell, 2001) for each Observatory with the software package EstimateS 8.20 (COLWELL, 2009) out of the $1,000-\mathrm{m}^{2}$ plot data with 1,000 randomizations without replacement of samples. I fitted six different asymptotic models (Michaelis-Menten [7], negative exponential [8], rational [9], logistic [10], Lomolino [11], and asymptotic regression function [12]; Table 3-1) to the resulting curves with the non-linear leastsquare method (function 'nls' in R (R Development Core Team, 2008)). For model selection, I used the $\triangle$ AICc scores, calculated with the log-likelihood method (BURnHAM \& ANDERSON, 2004). I ranked the functions according to their $\triangle \mathrm{AICc}$ scores. For the three best ranked models, I 
determined the asymptotic levels which are equivalent to the total species richness of the Observatories (Dengler \& Oldeland, 2010).

Table 3-1: Overview of the models used for fitting species-area and species-sampling relationships with $S=$ species richness, $b_{x}=$ parameters of the applied models, and $A=$ sampled area.

\begin{tabular}{|c|c|c|c|c|c|}
\hline No. & Model name & Model & Parameters & Asymptote & Source \\
\hline 1 & Linear function & $S=b_{0}+b_{1} A$ & 2 & No & $\begin{array}{l}\text { CONNOR \& } \\
\text { MCCoy (1979) }\end{array}$ \\
\hline 2 & Power function & $S=b_{0} A^{b_{1}}$ & 2 & No & $\begin{array}{l}\text { ARrHENIUS } \\
(1920), \text { TJøRVE } \\
(2003)\end{array}$ \\
\hline 3 & $\begin{array}{l}\text { Power function } \\
\text { (quad.) }\end{array}$ & $\begin{aligned} S & =10^{\wedge}\left(b_{0}+b_{1} \log (A)\right. \\
& +b_{2}\left(\log (A)^{2}\right)\end{aligned}$ & 3 & No & $\begin{array}{l}\text { CHIARUCCI et al. } \\
\text { (2006) }\end{array}$ \\
\hline 4 & $\begin{array}{l}\text { Power function } \\
\text { (Plotkin, approx.) }\end{array}$ & $S=b_{0} A^{b_{1}} \exp \left(b_{2} A\right)$ & 3 & No & $\begin{array}{l}\text { PLOTKIN et al. } \\
(2000)\end{array}$ \\
\hline 5 & $\begin{array}{l}\text { Logarithmic } \\
\text { function }\end{array}$ & $S=b_{0}+b_{1} \log (A)$ & 2 & No & $\begin{array}{l}\text { Gleason (1922), } \\
\text { TJøRVE (2003) }\end{array}$ \\
\hline 6 & $\begin{array}{l}\text { Logarithmic } \\
\text { function (quad.) }\end{array}$ & $S=\left(b_{0}+b_{1} \log (A)\right)^{2}$ & 2 & No & $\begin{array}{l}\text { GITAY ET AL. } \\
(1991)\end{array}$ \\
\hline 7 & $\begin{array}{l}\text { Michaelis- } \\
\text { Menten (Monod) } \\
\text { function }\end{array}$ & $S=b_{0} A /\left(b_{1}+A\right)$ & 2 & Yes $\left(b_{0}\right)$ & $\begin{array}{l}\text { TJøRVe (2003), } \\
\text { Kluth \& } \\
\text { BRuelHeide } \\
(2004)\end{array}$ \\
\hline 8 & $\begin{array}{l}\text { Negative } \\
\text { exponential } \\
\text { function }\end{array}$ & $S=b_{0}\left(1-\exp \left(-b_{1} A\right)\right)$ & 2 & Yes $\left(b_{0}\right)$ & TJøRVE (2003) \\
\hline 9 & Rational function & $S=\left(b_{0}+b_{1} A\right) /\left(1+b_{2} A\right)$ & 3 & Yes $\left(b_{1} / b_{2}\right)$ & TJøRVE (2003) \\
\hline 10 & Logistic function & $S=b_{0} /\left(1+\exp \left(-b_{1} A+b_{2}\right)^{\prime}\right.$ & 3 & Yes $\left(b_{0}\right)$ & TJøRVE (2003) \\
\hline 11 & $\begin{array}{l}\text { Lomolino } \\
\text { function }\end{array}$ & $S=b_{0} /\left(1+\left(b_{1}^{\log \left(b_{2} / A\right)}\right)\right)$ & 3 & Yes $\left(b_{0}\right)$ & $\begin{array}{l}\text { LOMOLINO } \\
(2000), \text { TJøRVE } \\
(2003)\end{array}$ \\
\hline 12 & $\begin{array}{l}\text { Asymptotic } \\
\text { regression } \\
\text { function }\end{array}$ & $S=b_{0}-b_{1} b_{2}^{-A}$ & 3 & Yes $\left(b_{0}\right)$ & TJøRVE (2003) \\
\hline
\end{tabular}

\subsubsection{Non-parametric richness estimators}

I applied four incidence-based richness estimators (Colwell \& Coddington, 1994, Magurran, 2004) namely Chao 2 richness estimator (CHAO, 1987), first-order and second-order Jackknife (Jackknife 1 \& 2) (Burnham \& Overton, 1979), and Bootstrap richness estimator (Smith \& BeLLE, 1984). All these richness estimators were developed for incidence-based data sets and their 
calculation based on the occurrence of uniques $\left(Q_{1}\right)$ and duplicates $\left(Q_{2}\right)$ in the sample, which are species that only occur once and twice in the data set, respectively. For equations and more detailed explanations of these estimators, see table 3-2 and in MagurRan (2004). For the calculation, I made use of the software package EstimateS Version 8.20 (Colwell, 2009) taking 1,000 randomizations without replacement of samples.

Table 3-2: Overview over applied non-parametric richness estimators with $S_{\text {obs }}=$ total number of observed species, $\mathrm{Q}_{j}=$ number of species that occur in exactly $j$ samples, $m=$ total number of samples, $\mathrm{p}_{k}=$ proportion of samples that contain species $k$.

\begin{tabular}{|c|c|c|c|}
\hline No. & Estimator & Equation & Source \\
\hline 1 & Chao 2 estimator & $S_{\text {Chao } 2}=S_{\text {Obs }}+\frac{Q_{1}^{2}}{2 Q_{2}}$ & СНАО (1987) \\
\hline 2 & $\begin{array}{l}\text { First-order Jackknife } \\
\text { estimator }\end{array}$ & $S_{J a c k l}=S_{O b s}+Q_{1}\left(\frac{m-1}{m}\right)$ & $\begin{array}{l}\text { BuRNHAM \& OVERTON } \\
(1979)\end{array}$ \\
\hline 3 & $\begin{array}{l}\text { Second-order } \\
\text { Jackknife estimator }\end{array}$ & $S_{\text {Jack } 2}=S_{o b s}+\left[\frac{Q_{1}(2 m-3)}{m}-\frac{Q_{2}(m-2)^{2}}{m(m-1)}\right]$ & $\begin{array}{l}\text { BURNHAM \& OVERTON, } \\
(1979)\end{array}$ \\
\hline 4 & Bootstrap estimator & $S_{B o o t}=S_{O b s}+\sum_{S_{O b s}}^{k=1}\left(1+p_{k}\right)^{m}$ & Smith \& Belle (1984) \\
\hline
\end{tabular}




\subsection{Results}

\subsubsection{Observed species richness}

For both Observatories combined, I observed 213 plant species; 171 were found on the 20 plots of Duruchaus and 146 on Narais. Accumulated with the observed species from the BIOTA monitoring scheme sampled between 2005 and 2009, 261 plant species were recorded in the area of both Observatories, 216 on Duruchaus, 195 on Narais. Figure 3-1 shows distribution of species richness at the different sampled scales.
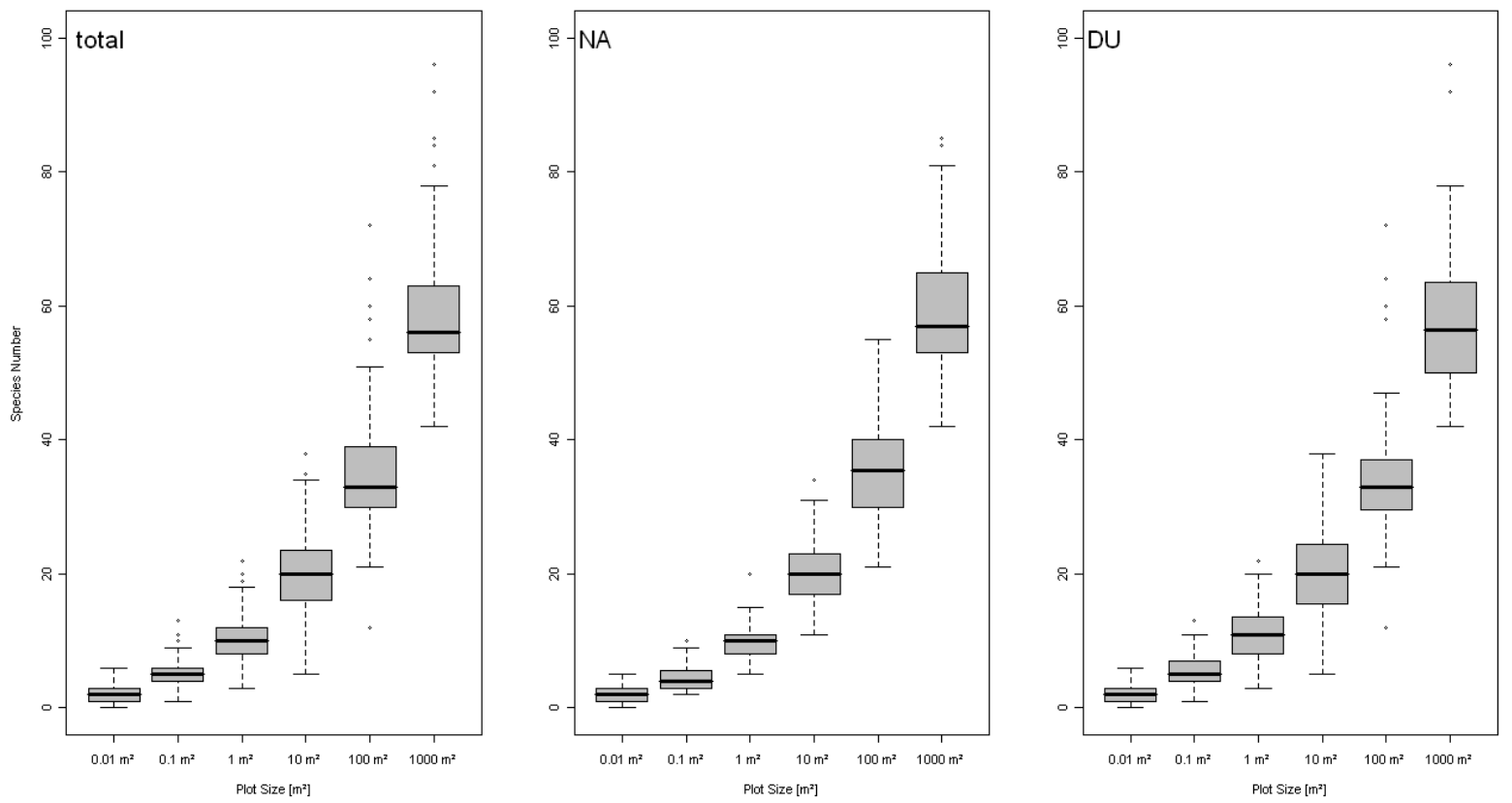

Figure 3-1: Boxplots of species richness per sampling scale for both Observatories (total) and separated for Narais (NA) and Duruchaus (DU).

\subsubsection{SAR: model selection for extrapolation}

The normal power function showed the best overall performance in model fitting by achieving the highest mean rank of both goodness-of-fit metrics; the first rank for $\triangle \mathrm{AICc}$ scores and the second for LEE values. The following models were the quadratic logarithmic and the quadratic power function. They are contrasted by their specific performance to the two goodness-of-fit measures: the quadratic logarithmic function showed an outstanding $\triangle \mathrm{AICc}$ score, the quadratic power function excellent values for the LEE. The Michaelis-Menten function ended up at the third $\triangle \mathrm{AICc}$ rank but showed considerably higher mean $\triangle \mathrm{AICc}$ values than the first two ranks (four times higher than second rank). Regarding the LEE, it was placed on the 7th rank only. 
Because of the bad combined performance (mean rank 5), I rejected this function for extrapolation. The Lomolino function resulted in the third LEE rank. With an average LEE close to $0(-0.051)$, it seems to be an appropriate model for extrapolation purposes. Taking only onetenth of the totally sampled area into account, it underestimated the actual species on the larger scale only by $9.5 \%$ in average. All other models performed worse and were rejected for extrapolation; for a summary, see Table 3-3. According to this ranking, I chose the power, quadratic power, quadratic logarithmic, and Lomolino functions for extrapolation to $1 \mathrm{~km}^{2}$ (Figure 3-2).

Table 3-3: Ranking of fitted species-area relation (SAR) models to the applied goodness-of-fit metrics. Mean rank of both metrics ( $\triangle \mathrm{AICc}$, LEE), rank $\triangle \mathrm{AICc}$, rank LEE, mean values of $\triangle \mathrm{AICc}, \mathrm{LEE}$, and $w_{i}$ for all plots.

\begin{tabular}{llcccccc}
\hline No. & Model name & Mean rank & $\begin{array}{l}\text { Rank } \\
\Delta \text { AICc }\end{array}$ & $\begin{array}{c}\text { Rank } \\
\text { LEE }\end{array}$ & $\Delta$ AICc & $w_{i}$ & LEE \\
\hline 1 & Linear function & 10 & 8 & 12 & 25.525 & 0 & 0.677 \\
2 & Power function & 1.5 & 1 & 2 & 2.133 & 0.61 & 0.045 \\
3 & Power function (quad.) & 3.5 & 6 & 1 & 23.580 & 0 & -0.029 \\
4 & Power function (Plotkin, & 10 & 9 & 11 & 25.690 & 0 & -0.577 \\
& approximate) & & & & & & \\
5 & Logarithmic function & 4.5 & 4 & 5 & 20.654 & 0 & -0.185 \\
6 & Logarithmic function & 3 & 2 & 4 & 4.658 & 0.39 & -0.064 \\
& (quad.) & & & & & & \\
7 & Michaelis-Menten & 5 & 3 & 7 & 19.807 & 0 & -0.232 \\
& (Monod) function & & & & & & \\
8 & Negative exponential & 7.5 & 5 & 10 & 22.194 & 0 & -0.246 \\
& function & & & & & & \\
9 & Rational function & 10 & 12 & 8 & 51.419 & 0 & -0.230 \\
10 & Logistic function & 5 & 7 & 3 & 25.046 & 0 & -0.051 \\
11 & Lomolino function & 10 & 11 & 9 & 46.257 & 0 & -0.235 \\
12 & Asymptotic regression & & & & & & \\
\hline
\end{tabular}



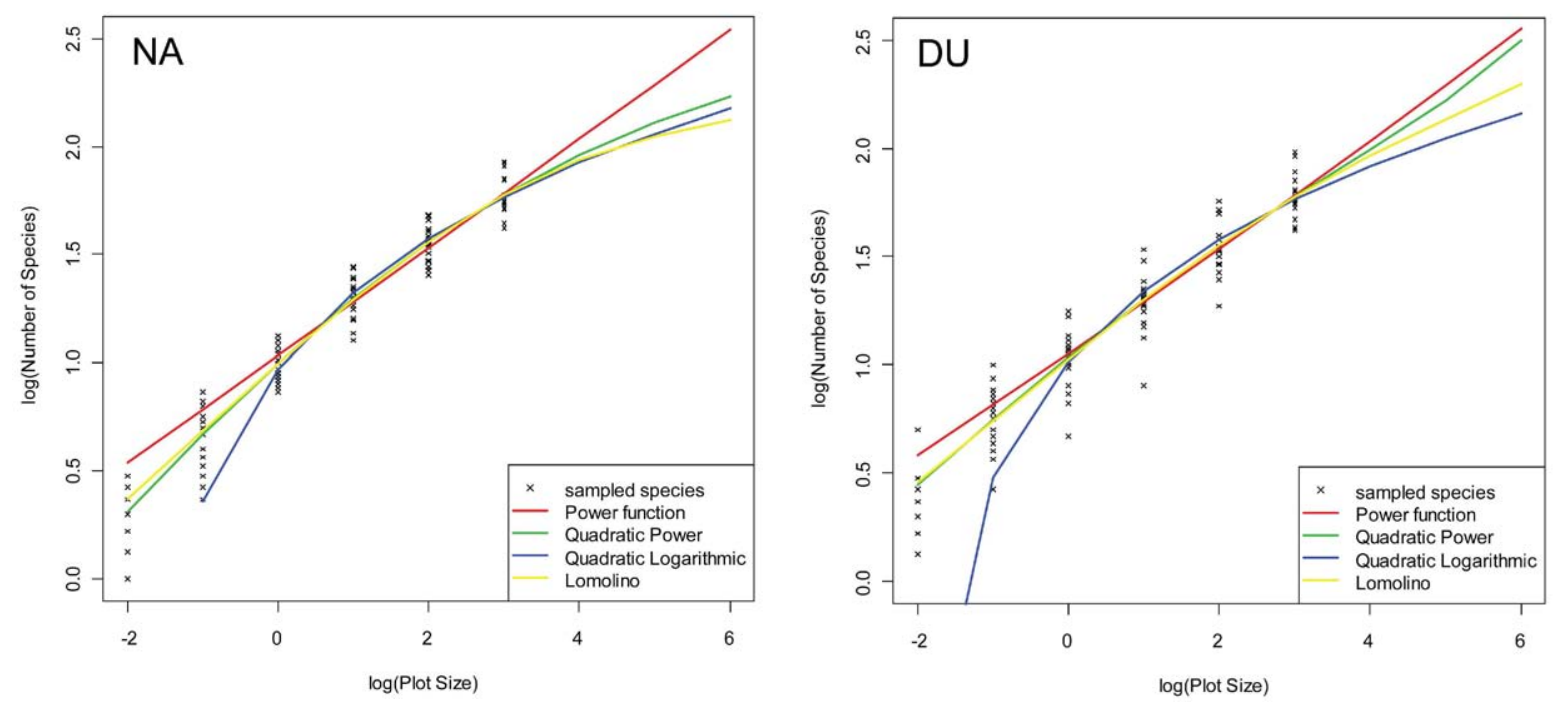

Figure 3-2: Extrapolation of selected SAR functions to $1 \mathrm{~km}^{2}$ (for better presentation in log-logtransformation which was not used for curve fitting).

\subsubsection{SSR: model selection for extrapolation}

By far the best performing model to fit the species accumulation curves according to $\triangle \mathrm{AICc}$ was the Lomolino function, followed by the rational function and asymptotic regression function. I selected these three models to have a broad range of extrapolation estimates (Figure 3-3). Michaelis-Menten, logistic, and negative exponential function showed considerably higher $\triangle$ AICc values (Table 3-4).

Table 3-4: Ranking and mean $\triangle$ AICc of applied SSR models.

\begin{tabular}{llc}
\hline Rank & Model name & Mean $\Delta$ AICc \\
\hline 1 & Lomolino function & 0.00 \\
2 & Rational function & 67.14 \\
3 & Asymptotic Regression function & 90.25 \\
4 & Logistic function & 111.00 \\
5 & Michaelis-Menten (Monod) function & 120.73 \\
6 & Negative exponential function & 145.28 \\
\hline
\end{tabular}



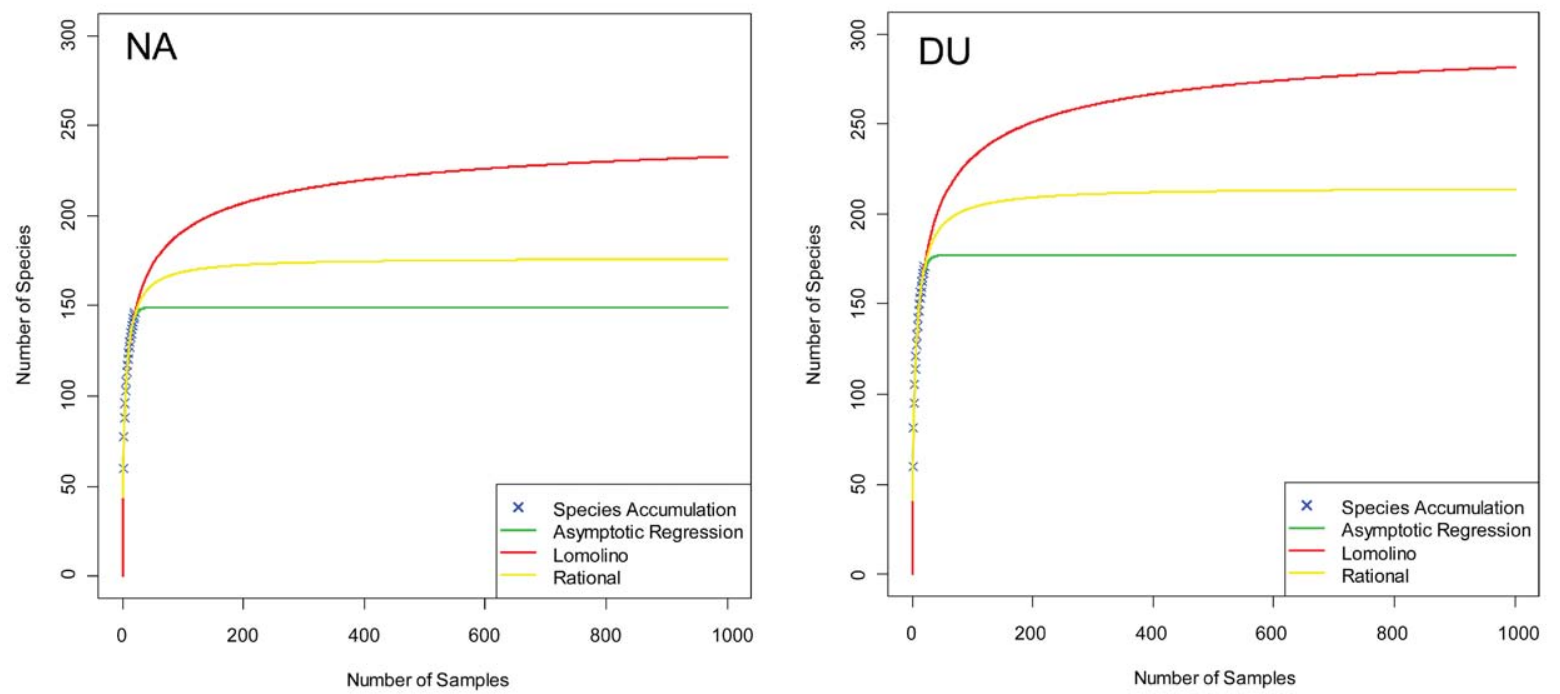

Figure 3-3: Extrapolation of selected SSR functions to $1 \mathrm{~km}^{2}$ (스 1000 samples à $1000 \mathrm{~m}^{2}$ ) for the Observatories Narais (NA) and Duruchaus (DU).

\subsubsection{Extrapolation to $1 \mathrm{~km}^{2}$}

On both Observatories, the highest species richness estimates were given by extrapolating of the power SAR function (347 on Narais, 355 species on Duruchaus), lowest estimates on Narais by the Lomolino function (132 species), on Duruchaus by the quadratic Logarithmic function (148 species). The difference between the highest and the lowest estimates amounted to more than 200 species, what was more than the actually observed species richness on the Observatories. The SAR functions with the best extrapolation quality according to the LEE (quadratic power and power) and the $w_{i}$-weighted mean resulted in exceptional higher species estimates (except quadratic power for Narais) than all other models or estimators. The values of the non-parametric estimators resulted in medium range estimates as well as asymptotic regression and rational SSR models. Looking at the curve shape of the non-parametric estimators, none of the estimators reached the saturation level demanded for a high reliability at Narais Observatory; at Duruchaus at least the estimators Chao 2 and Jackknife $1 \& 2$ came close to an asymptote after inclusion of 16 samples (Figure 3-4).

Generally, the estimates for the Duruchaus Observatory range between 20 and 30 more species than for Narais. The actually observed and accumulated species richness showed a similar divergent trend of species richness between the two Observatories. For the power and quadratic 
logarithmic SAR function, the estimates for the Observatories did not differ considerably. The latter was the sole method resulting in slightly higher values for the Narais Observatory.

Table 3-5: Vascular plant species richness estimated for the area $\left(1 \mathrm{~km}^{2}\right)$ of the Observatories with different methods. The methods grouped into four categories: (1) data from sampling, (2) extrapolation of species-area relationships (SARs), (3) extrapolation of species-sampling relationships (SSRs), and (4) non-parametric Estimators.

\begin{tabular}{llcc}
\hline Method & Name & $\begin{array}{l}\text { Duruchaus } \\
\text { (mean } \pm \text { standard error) }\end{array}$ & $\begin{array}{l}\text { Narais } \\
\text { (mean } \pm \text { standard error })\end{array}$ \\
\hline (1) Sample & Observed species richness & 171 & 146 \\
& Accumulated species richness & 216 & 195 \\
\hline (2) SARs & Power & $355 \pm 37.35$ & $347 \pm 24.96$ \\
& Power quad. & $314 \pm 85.48$ & $170 \pm 16.19$ \\
& Logarithmic quad. & $148 \pm 10.15$ & $151 \pm 8.61$ \\
& Lomolino & $160 \pm 24.96$ & $132 \pm 9.61$ \\
& $w_{i}$-weighted mean & $295 \pm 41.01$ & $273 \pm 28.13$ \\
\hline (3) SSRs & Asymptotic Regression & 177 & 149 \\
& Lomolino & 308 & 260 \\
& Rational & 215 & 177 \\
\hline (4) Non- & Chao 2 & 192 & 176 \\
parametric & Jackknife 1 & 208 & 177 \\
Richness & Jackknife 2 & 215 & 193 \\
estimators & Bootstrap & 190 & 160 \\
\hline
\end{tabular}
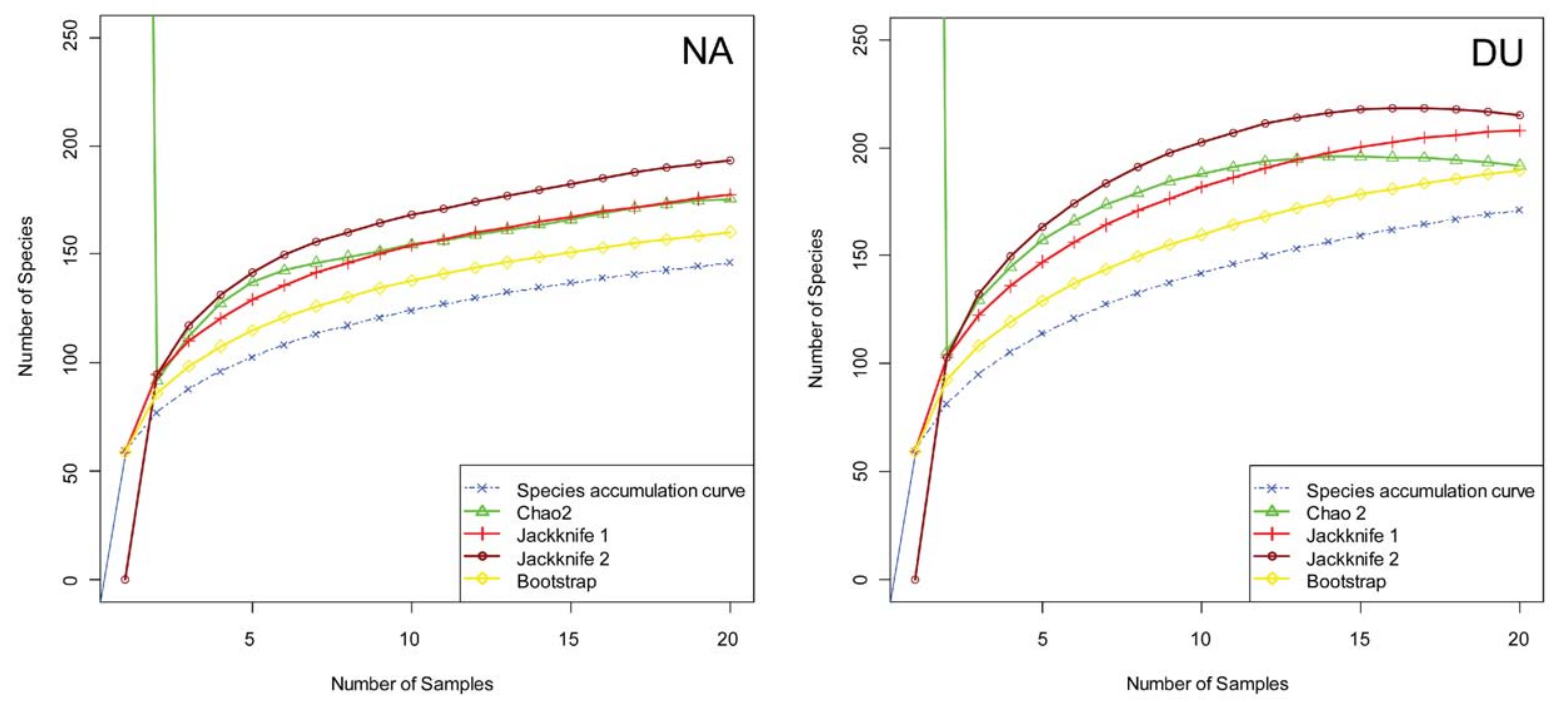

Figure 3-4: Species accumulation curves and curves of non-parametric species richness estimators of the Observatories Narais (NA) and Duruchaus (DU). 


\subsection{Discussion}

\subsubsection{SAR and SSR model selection}

The normal power function first proposed by ARRHENIUS (1921) was the overall best SAR model in my study. It performed well in curve fitting ( $\triangle \mathrm{AICc}$ rank 1$)$ and extrapolation capability (LEE rank 2). Additionally, it gave reasonable total species richness estimates for both Observatories (see section 3.4.2.). These findings strongly support the conclusion of Dengler (2009b), who proposed the use of the normal power function to describe and compare any kind of SARs. He pointed out the following advantages of this function: i) it shows no upper asymptote and is thereby theoretical suitable for extrapolation to bigger areas than sampled, ii) its two parameters $c$ and $z$ are quite stable and interpretable and on the other hand flexible enough to well fit most of ecological datasets, and iii) the results stay comparable to a multitude of past and recent studies dealing with species-area relationships. In his study, Dengler (2009b) found the normal power function to be superior among the two-parameter models, which showed an excellent extrapolation performance (Dengler, 2009b). Also in some seminal publications (Preston, 1962; MacArthur \& Wilson, 1967; RosenzWeig, 1995) the exclusive use of power-law SAR function has been proposed. In Dengler's study (2009b), the quadratic power and the Lomolino function fit best the data derived from a nested-plot sampling with a comparable design to my study. For my data, these functions also reached extraordinary results regarding the extrapolation capability (LEE rank 1 and 3) but failed in curve fitting measured in the $\triangle \mathrm{AICc}$ ranking (rank 6 and 7). The quadratic logarithmic model that was stated as inadequate by Dengler (2009b) performed well in regards to curve fitting ( $\triangle \mathrm{AICc}$ rank 2$)$ as well as in extrapolation capacity (LEE rank 4). In contrast, Stiles \& SCheiner (2007) argued that the power function should not be used as a unique model to describe the species-area relationship. They showed in their study - comparing field data from an arid ecosystem in the Sonoran Desert, USA - that the power function in most cases failed to fit the SAR appropriately. They found rational, logistic, and Lomolino functions to perform much better in herbaceous plant communities. However, their findings should be differentiated from mine for the simple reason that Stiles \& Scheiner (2007) used divergent methodology for sampling and understanding of species-area curve typology. STILEs \& SCHeIner (2007) used non-contiguous plots arranged in transects at different distinct locations. Following 
the typology of SCHEINER (2003) these SARs are of type IIIB (non-contiguous, adjacent, means of replications) but according to the modified typology by DenGLER (2009b) these curves should not be signified as SAR but as species sampling relationships (SSR). The latter argued that SAR and SSR have fundamental different properties and thus should be distinguished. While SAR models are theoretical always non-asymptotic functions, SSR models reach an asymptotic level which give the total species richness of the observed area (Dengler, 2009b). The two types (SAR and SSR) have to be separated also for practical reasons: SSR constructed from non-contiguous plots give higher richness values because of spatial autocorrelation while a broader heterogeneity of habitats could be sampled. In the typology of SCHEINER (2003), my data belongs to the type IIa of SARs, constructed from fully nested, contiguous samples with averaged values from three replicates per plot. Dengler (2009b) named these curves as 'real' SAR.

I showed in my study - applying a SAR as well as a SSR approach to field data - that i) model analyses of SAR and SSR resulted in different best fitting function types and should be separated, which Dengler (2009b), Dengler \& Oldeland (2010), and Smith (2010) already pointed out, and ii) SARs were best described by power, SSR by rational and Lomolino functions. These findings were completely in line with the results of DENGLER (2009b) for SAR as well as with these of STILEs \& SCHEINER (2007) for SSR.

\subsubsection{Average weighted by Akaike Weights $\left(w_{i}\right)$}

Additionally, I calculated an average extrapolation value from all plots and tested models weighted by the Akaike Weights $\left(w_{i}\right)$ (Akaike, 1978, 1979; Burnham \& Anderson, 2002). The Akaike Weights $\left(w_{i}\right)$ give a tool to interpret the probability of each model to fit the given data. This approach allows to pick not only the extrapolation result of the overall best fitting model according to the $\triangle \mathrm{AICc}$ but also benefit from the explanatory value of inferior models. In my study, the application of a $w_{i}$-weighted mean gave a reasonable estimating result ranging in between the other SAR model's extrapolations (see previous chapter 3.4.1.).

Nevertheless, I do not recommend the use of this method because it constricts the comparability of extrapolation results within the study and to other studies. For each individual plot, different models in different proportions were taken into account. General assumptions on model selection were masked under these circumstances. Amongst different biodiversity studies, the results remain 
comparable only as long as the same set of models is used and the importance of each model according to the Akaike Weights $\left(w_{i}\right)$ is clearly illustrated. Furthermore the $w_{i}$-weighted mean provided almost no additional information in this study because the extrapolation average mainly consisted of the results of two models; the dominant normal power ( $60 \%$ average weight) and the quadratic logarithmic function (39\% average weight). Other models had hardly any influence on the result. Comparing the results of the single functions seems to be a more clear and transparent approach for species richness estimations via SAR extrapolation.

\subsubsection{Selection measurements}

The used methods for SAR model selection were proposed by DeNGLER (2009b). The $\triangle A I C c$ is a recently widely applied measure for model selection (Burnham \& ANDERson, 2002) that on the one hand values the goodness-of-fit of the model to the input data and on the other hand sticks to the principle of parsimony (SoBER, 1981) by penalising higher amount of model parameters. Therefore, it has to be favoured to the often used $R_{\text {adj }}^{2}$ (e.g. Flather, 1996, Thompson et al., 2003). $R_{\text {adj }}^{2}$ only values the deviation of the model from the data but not the number of parameters (Colwell et al., 2004, Dengler, 2009b). As two functions with only two parameters achieved the best $\triangle \mathrm{AICc}$ scores in this study, namely the normal power and the quadratic logarithmic function, they were favoured over functions with more parameters.

Extrapolation is one of the major applications of SAR models (COLWELl \& Coddington, 1994; He \& Legendre, 1996; Plotkin et al., 2000; Dengler \& Oldeland, 2010) and therefore, it is not only important to know the model's fit to the sampled data but also the precision of species richness estimates to larger areas. For this reason, Dengler (2009b) introduced the LEE to give a suitable measurement for evaluating the extrapolation capability of a SAR model to larger areas than sampled. The omittance of all data referring to subplots larger than one-tenth of the largest area seems to be reasonable to fulfil this need. SCHEINER (2009) stated the LEE to be 'a very useful measure of the accuracy of extrapolations'. In this study, the LEE operated as an useful indicator to select the best extrapolating models. Thus, the quadratic power function which got the first LEE rank presumably gave a realistic species richness estimate at least for the Duruchaus Observatory, the normal power function (LEE rank 2) realistic ones for both Observatories (see section 3.4.4). By contrast, the good LEE rank 3 of the Lomolino function was misleading 
because this function resulted in too low estimated species richness at both Observatories. One reason could be the asymptotic type of this function. The Lomolino models using the data from 0.01 till $1,000 \mathrm{~m}^{2}$ samples reached their asymptotic level close to the extrapolated scale of $1 \mathrm{~km}^{2}$. At this section of the function, the slope is very gently ascending and thus the model gives relatively low species richness results for the point at $1 \mathrm{~km}^{2}$.

\subsubsection{Logarithmic transformation}

I did not use log-transformation as in the original introduction of the SAR as a power function by Arrhenius (1921) and in many following studies (e.g. McArthur \& Wilson, 1967; RosenzWeig, 1995). The advantage of log-transformation is the possibility to fit power functions easily as linear regression to the data. In recent years, computer power became available to fit non-linear models (Lomolino, 2001; Stiles \& SCheiner, 2007). I expected no additional gain of insight by log-transformed models because their results normally only differ negligibly. DenGLer (2009b) pointed out that the extrapolation capability of SAR models with the non-transformed data is even better than in a $\log$-transformed manner. The indefiniteness of $\log (0)$ is another problem of the appliance of log-transformation in my study. Some of the smallest scale plots $\left(0.01 \mathrm{~m}^{2}\right)$ did not contain any species. In this case, it would be crucial to work with mean species values of this plots or to use a $\log (S+x)$-transformation instead of the simple log-transformation.

\subsubsection{Evaluation of species richness estimates}

In order to compare the resulting estimates regarding bias and accuracy (WaLther \& Moore, 2005) and to determine the reliability of the tested estimators definitively (CHIARUCCI et al., 2001), the 'true' total species richness data of the target area $\left(1 \mathrm{~km}^{2}\right)$ as complete as possible is needed (PAlmer, 1990; WeI, 2010). However, with reasonable time and personnel effort, it is nearly impossible to sample such a large area (PALmer, 1995; Gaston, 1996). In this study, the best educated guess of the total species richness by actually sampled data is provided by the accumulated data of the BIOTA monitoring project. It included all vascular plant taxa that have been found on the two Observatories between 2005 and 2009. The BIOTA project did not conduct a systematic census of all occurring plant species but tried to cover the major habitats existing on the Observatories by a ranking of the grid cells and monitoring over different years 
(JüRGENS et al., submitted). A broader range of habitats and wider time span over four years have been sampled than in the sampling scheme of this study. Also rare species occurring only on some special sites (Aloe littoralis, Hoodia gordonii) or sporadically emergent species establishing only during wet rainy seasons (geophytes like Ferraria glutinosa, Ursinia nana) could be recorded with the higher sampling effort in time and space. Hence, it illustrated only an estimate at the lower margin of species richness at the Observatories but came closer to the total species richness than the observed species richness. The observed species richness of sampled plots is a bad indicator for total species richness of a studied area (Palmer, 1991; Chiarrucci et al., 2003; Walther \& Moore, 2005). Only a small percentage of the total area was covered $\left(20,000 \mathrm{~m}^{2}\right.$ within each 1 $\mathrm{km}^{2}$ Observatory $=2 \%$ ) and as a shortcoming of the random sampling scheme used, many special sites (e.g. pans, drainage lines, or termite mounds), where probably additional species have been found, were not sampled. All other applied estimators resulted in higher species richness than observed species richness of this study and consequently performed better to come closer to the total species richness. Thus, it should be avoided in ecological studies to use only the observed species richness as a value for the total richness of a distinct site. Every estimator would give more reliable results (Palmer, 1991; Chiarrucci et al., 2003; Walther \& Moore, 2005; Wei et al., 2010). Furthermore, I can assume that estimators resulting in lower species richness than the accumulated records are negatively biased. All non-parametric estimates and most SAR and SSR models did fulfil this assumption; only power SAR functions, the $w_{i}$-weighted mean of all models, and Lomolino SSR function on both Observatories and the quadratic power SAR function on Duruchaus pointed at considerably higher species richness. However, the results of the nonparametric estimator Jackknife 1 and in particular Jackknife 2 came very close to the accumulated species richness and were thereby appropriate to give at least a conservative estimation of the species richness.

These results cast doubt on the frequently claimed superiority of the non-parametric estimators over other approaches of richness estimation (Palmer, 1990; Colwell \& Coddington, 1994; MagurRan, 2004); a doubt, that was already expressed by other researchers (CondiT et al., 1996; Chiarrucci et al. 2003, 2006; Wei et al., 2010). A reason for the weak performance of all nonparametric richness estimators in this study could be the small sampled proportion of the total 
area (2\%). From evaluative studies with field and simulated data, CHIArrucCi et al. $(2003,2006)$ demanded at least $15-30 \%$ of the concerned area to be sampled to get reliable estimates with nonparametric estimators. Nevertheless, the $2 \%$ sampled area was already more than in most comparable biodiversity studies at this intermediate spatial scale (SKOV \& LAWESSON, 2000, Chiarrucci et al., 2001; Chiarrucci \& Palmer, 2006). An indicator for the undersampling in my study was that most of the non-parametric estimators did not reach a stable asymptote after the integration of all sampled plots, whereas a stable asymptote of an estimator indicates a sampling effort sufficient to get a reliable estimate (Gotell \& Colwell, 2001). In this case, no higher richness value will be received, even if more samples are added to the calculation. In comparable species richness studies, the estimators did not reach an asymptote either (SKOV \& LawessON, 2000, Chiarrucci et al., 2001).

The SAR functions with the best extrapolation quality according to the LEE (normal and quadratic power function) resulted in exceptional higher species estimates (except quadratic power at Narais) than all other models or estimators. The $w_{i}$-weighted mean of SAR functions and the Lomolino SSR resulted in estimates a little lower than power SAR. I assume these high values to be reasonable because I sampled only a small percentage $(2 \%)$ of the total area. Thus, I probably missed some special habitats with new species records. A reliable species richness estimate ranged from 260 to 350 on Narais, 310 to 350 species on Duruchaus. These estimates added up to around twice the number of recorded species in the present study and 100 species more per Observatory than in the accumulated data of the BIOTA monitoring.

\subsubsection{Differences between Observatories}

The actually sampled species richness and nearly all estimators showed slightly higher species richness on Duruchaus than on Narais. One possible reason for this difference could be the differing geomorphological properties of the Observatories. The Duruchaus Observatory holds a higher spatial heterogeneity due to deeper drainage lines and steeper slopes than on Narais (Schatre-Schlüterhof, 2008). In these drainage lines and on their slopes, the compact chalk crust is removed so that shrub and tree species (e.g. Ziziphus mucronata) can root deeper in the soil. The trees and shrubs themselves create new shadowed habitats for herbal species. These two factors contribute to higher species richness on Duruchaus. BuRnETt et al. (1998) showed that 
especially the heterogeneity of aspect and soil drainage could significantly increase plant species richness. The Narais Observatory, on the other hand, is characterized by small pan structures featuring special site conditions. After heavy rainfall events, they are inundated because the water cannot drain into the impermeable clay soils and no outlets exist. During dry spells, they dry out completely and the clayey surface soils indurate (Mendelsohn et al., 2009). Under these conditions, a relatively uniform vegetation dominated by annual grass species develops. At the edges, trees and shrubs grow. Additionally, the pans show high long term variability in species composition due to precipitation progression over years (Rogers, 1997; D. Wesuls, unpublished data). Depending on the rhythm of inundation and drying-up, different species from the soil seed bank emerge and come to dominance. Probably some potential plant species were missed at these special sites in the limited years of sampling.

Another reason could be the lower grazing intensity on the Narais farm. Grazing as a disturbance of the vegetation can prevent the dominance of single species and therefore increase plant species richness at an intermediate disturbance level (intermediate disturbance hypothesis (GRIME, 1973; Connell, 1978)). The low grazing intensity at Narais Observatory could lead to the dominance of certain species (e.g. Eragrotis nindensis, Stipagrostis ciliata) and thus to a lower species richness than at the stronger grazed Duruchaus farm (OlfF \& Ritchie, 1998).

\subsection{Conclusion}

I showed that the SAR extrapolation approach gave reasonable results to estimate species richness at the intermediate scale and performed better than other methods like SSR or non-parametric species estimators. Especially the use of non-parametric estimators should be questioned for vegetation surveys at an intermediate spatial scale. Furthermore, SARs should be clearly separated from SSRs and other accumulation curves because they differ considerably in sampling methodology and model types. Direct comparisons of these two methods are not feasible. To get a confirmed overview of the performance of this broad set of estimation methods, definitely more studies including field and simulated data of different taxonomic groups are needed. For medium scale vegetation surveys, I recommend the use of a comprehensive standardised multi-scale design like proposed by DENGLER (2009a) in order to enable the application of SAR functions for reliable species richness extrapolation to larger scales than sampled, and to get results comparable to other 
richness estimators. This approach delivers a powerful tool to access reasonable species richness values as decision-making instrument for nature conservation and land use management on a landscape scale. 


\section{How does differing grazing intensities influence plant diversity patterns at various spatial scales? Comparison of the BIOTA-Observatories Narais and Duruchaus in central Namibia}

\subsection{Introduction}

In semi-arid ecosystems, like the savannas of central Namibia, livestock grazing could be a major cause for rangeland degradation and threat to plant diversity (WALKER et al., 1981; Illius \& O'Connor, 1999). The consequences of grazing on semi-arid grasslands are ambiguous: light grazing can lead to an increase in species richness because of the reduction of dominant species and therefore of competition, better nutrient availability through dung accumulation, or easier establishment due to the breaking up of the biological soil crusts (BSCs) by trampling (DE BELLO et al., 2007; Facelli \& Springbett, 2009); higher grazing intensities, in contrast, can cause a decrease in species richness. Under the stress of defoliation and trampling most plant species are reduced and only a few grazing resistant species can get dominant (WASER \& PrICE, 1981; NoyMEIR et al., 1989). Due to selective grazing, non-palatable species like toxic or thorny ones are favoured over palatable species (MiLton et al., 1994).

Since the impact of herbivory by livestock is not easily distinguishable from other site factors as climatic conditions, e.g. highly variable rainfalls, and soil properties, researchers have to find relatively homogeneous study areas in regard to these ecological drivers to filter out the original influence of grazing on the vegetation. For this reason, I chose the two directly adjacent BIOTAObservatories Narais and Duruchaus in central Namibia which are characterized by a strong fence line contrast due to differences in grazing intensity. Climatic conditions are the same on both Observatories and the variability of soil chemical properties was stated to be low (PETERSEN, 2008).

The pronounced fence line contrast has developed since the farmer of Narais changed his land use management by reducing stocking rates in the Observatory camp after a strong drought in the years 1981/82. The farmer of the Duruchaus farm continued with higher stocking rate at the limit of the carrying capacity because he could not afford management changes in his economical situation at that time (HaARMEYER et al., 2010). Since these years, the sharp fence line contrast developed mainly because of lower cover of vegetation and BSCs on Duruchaus. It can be seen on 
every aerial photograph as well as on satellite image of the area (HAARMEYER et al., 2010). The fence line contrast can be interpreted as an accidental long-term experiment of anthropogenic disturbance of an ecosystem (Noy-Meir et al., 1989; Todd \& Hoffman, 1999). For this reason, the two Observatories were established to investigate and monitor the impact of the different management strategies on the savanna ecosystem. Within the framework of the BIOTA Southern Africa project, the vegetation was studied on 20 1-ha plots per Observatory every year from 2004 to 2009. In addition, a detailed soil survey with a comparison of the physical and chemical soil properties was conducted on the Observatories (Petersen, 2008). In this study, I refined the vegetation analysis to smaller spatial scales and combined the sampling of vegetation data and soil properties. The main objectives were i) to describe and analyse the differences in plant diversity and vegetation characteristics like abundance and growth height under different grazing intensities on the two Observatories, ii) to examine the differences in floristic composition on both Observatories, and iii) to compare site properties of the Observatories sampled at the same

plots as the vegetation in order to find out how much they could impact vegetation attributes beside the influence of differing grazing intensities.

\subsection{Material \& Methods}

\subsubsection{Soil and site factor sampling}

I took a mixed topsoil sample from each $100-\mathrm{m}^{2}$ subplot by collecting a scoop of soil in each plot corner. For this purpose, I scraped away the BSCs before digging approximately $10 \mathrm{~cm}$ deep and measured the soil depth by driving in an $1 \mathrm{~m}$ long metal stick into the ground as far as it reached the solid bedrock surface. This procedure was repeated in each corner of the $100-\mathrm{m}^{2}$ plots, and an average depth was calculated.

At the same subplots, the cover of BSCs, litter, and stones in three different size groups $(<6 \mathrm{~cm}$, $6-20 \mathrm{~cm},>20 \mathrm{~cm}$ ) was estimated on the same percent scale as used for the vegetation sampling. I determined the altitude of the plots by reading from GPS device. Moreover, I recorded their topographic position applying the categories 'summit', 'shoulder', 'mid slope', 'foot slope', and 'toe slope'. I measured the inclination of the plots with the device Suunto PM-5 and the exposition with a magnetic compass. I estimated the maximal variation in the plot's relief in 10 
$\mathrm{cm}$ intervals by taking the maximal difference in the surface from drainage lines, ground waves, and small hills into account.

\subsubsection{Soil analysis}

For each $100-\mathrm{m}^{2}$ subplot, I dried a mixed topsoil sample in the air under hot, dry conditions in the field and analysed them in the laboratory. I measured electric conductivity (EC) in $\mathrm{H}_{2} \mathrm{O}$ with a standard conductivity cell (WTW Tetracon ${ }^{\circledR} 325$ ), $\mathrm{pH}$-values in a soil suspension in $\mathrm{H}_{2} \mathrm{O}$ and $\mathrm{CaCl}_{2}$ with a $\mathrm{pH}$ combination electrode (WTW Sentix 41) after Rowell (1997). I determined the chalk content $\left(\mathrm{CaCO}_{3}\right)$ with the Scheibler gadgetry (Eijkelkamp Calcimeter; DIN 19684). I measured the content of organic carbon as loss on ignition burned at $500{ }^{\circ} \mathrm{C}$ for 6 hours. To describe the soil texture, I sieved the samples with a scientific sieve ( $2 \mathrm{~mm}$ mesh size) in the field and weighted the oversized coarse soil fraction. In the lab, I distinguished the finer fractions (sand, silt and clay) with the standardised 'finger probe' (Ad-hoc-Arbeitsgruppe Boden, 2005).

\subsubsection{Data analysis}

To compare different diversity characteristics of the Observatories due to the grazing gradient, I applied two-samples permutation tests (function 'oneway_test' in package 'coin' (Hothorn et al., 2008) in R 2.7.0 (R Development Core Team, 2008) with a 95\% confidence interval (Manty, 2007). I tested the differences between the Observatories in species richness at different spatial scales by calculating the averaged values for each sampled plot size $(0.01,0.1,1,10,100,1,000$ $\left.\mathrm{m}^{2}\right)$, the Shannon-Index $\left(\mathrm{H}^{\prime}=-\Sigma \mathrm{p}_{\mathrm{i}}{ }^{*} \ln \left(\mathrm{p}_{\mathrm{i}}\right)\right)\left(\right.$ Shannon \& WeAver, 1949), and the Evenness $\left(\mathrm{E}^{\prime}=\right.$ $\left.\left(\mathrm{H}^{\prime} \mathrm{H}^{\prime}{ }_{\max }^{-1}\right)^{*} 100\right)$ (PIelou, 1966) of all $100-\mathrm{m}^{2}$ subplots as measures of $\alpha$-diversity. Furthermore, I calculated the mean $z$-values (slope of line between sequent plot sizes in double-logarithmic space) which describe the relative increase in species richness with increasing scale size, and the SAR-power-function exponent $z$ as measures of $\beta$-diversity. I applied a one-way analysis of variance (ANOVA) to test the dependency of the z-values on the spatial scales using the function 'aov' in R 2.7.0 (R Development Core Team, 2008).

I also tested the differences of selected biotic and abiotic site properties of the Observatories averaged for every $1,000-\mathrm{m}^{2}$ main plot with the two-samples permutation tests; namely total vegetation cover and maximum height, cumulated cover of annual and perennial plant species, cover of BSCs and bare soil, soil depth, $\mathrm{pH}$ measured in $\mathrm{H}_{2} \mathrm{O}$ and $\mathrm{CaCl}_{2}$, electric conductivity 
(EC), $\mathrm{CaCO}_{3}$-content, loss on ignition, percentage of coarse soil, and the maximum variation in the microrelief.

Finally, I performed an indicator species analysis (DufrêNe \& LeGENDRE, 1997) with the cover-based species lists of the $100-\mathrm{m}^{2}$ subplots to examine the main floristic differences of the studied Observatories. The indicator species analysis was done using the algorithm 'indval' from the 'labdsv' package (RoBerTs, 2007) available for the statistical computing language R 2.7.0 (R Development Core Team, 2008).

\subsection{Results}

For both Observatories combined, I observed 213 plant species belonging to 49 families and 143 genera, of which 171 were found on Duruchaus and 146 on Narais. At all sampled scales except the $100-\mathrm{m}^{2}$ plots, the richness was slightly higher on the Duruchaus Observatory than on Narais (Table 4-1) but the differences in species richness between both Observatories were not significant except for the scale of $0.1 \mathrm{~m}^{2}$.

Table 4-1: Average species richness of different sampled scales for the total study area and separated for the Observatories Narais and Duruchaus. The absolute minimum and maximum richness is given for all plots of the referred size. The significance level of the two-samples permutation tests ( $\mathrm{p}$-values) is given for the difference between averages of the Observatories $(n=$ 20).

\begin{tabular}{|c|c|c|c|c|c|c|c|c|c|c|c|}
\hline & \multicolumn{3}{|l|}{ Total } & \multicolumn{3}{|c|}{ Narais } & \multicolumn{3}{|c|}{ Duruchaus } & \multirow[b]{2}{*}{ Max. } & \multirow[t]{2}{*}{$\mathrm{p}$} \\
\hline & Av. & Min. & Max. & & Av. & Min. & Max. & Av. & Min. & & \\
\hline $0.01 \mathrm{~m}^{2}$ & 2.26 & 0 & & 6 & 2.13 & 0 & 5 & 2.38 & 0 & 6 & 0.285 \\
\hline $0.1 \mathrm{~m}^{2}$ & 5.08 & 1 & & 13 & 4.48 & 2 & 10 & 5.67 & 1 & 13 & 0.017 \\
\hline $1 \mathrm{~m}^{2}$ & 10.52 & 3 & & 22 & 9.92 & 5 & 20 & 11.12 & 3 & 22 & 0.157 \\
\hline $10 \mathrm{~m}^{2}$ & 20.23 & 5 & & 38 & 20.08 & 11 & 34 & 20.37 & 5 & 38 & 0.856 \\
\hline $100 \mathrm{~m}^{2}$ & 35.29 & 12 & & 72 & 35.57 & 21 & 55 & 35.2 & 12 & 72 & 0.834 \\
\hline $1000 \mathrm{~m}^{2}$ & 59.75 & 42 & & 96 & 59.65 & 42 & 85 & 59.85 & 42 & 96 & 0.963 \\
\hline
\end{tabular}

According to the indicator species analysis, the perennial grasses Eragrostis echinochloidea and Stipagrostis uniblumis, the annual grass Enneapogon desvauxii, and dwarf shrubs like Leucosphaera bainesii, Aizoon schellenbergii, and Eriocephalus luederitzianus are diagnostic for the vegetation on the Narais Observatory (Table 4-2). On Duruchaus Observatory, the vegetation is mainly 
characterized by the perennial grass Stipagrostis obtusa and Stipagrostis ciliata and the dwarf shrubs Monechma genistifolium, Melolobium adenodes, and Melolobium microphyllum (Table 4-3). A visual impression of the vegetation composition on the Observatories is provided by Figure 4-1.
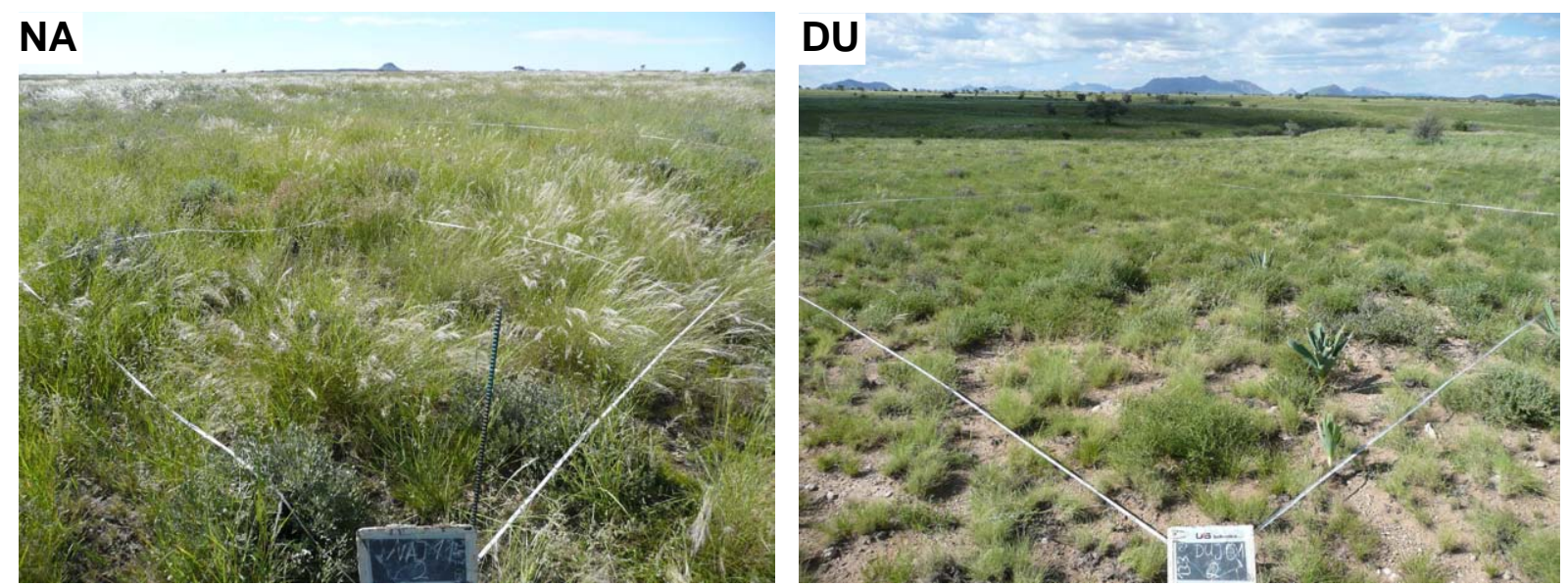

Figure 4-1: Impression of vegetation composition on the Observatories Narais (NA) and Duruchaus (DU).

Table 4-2: List of indicator species of Narais Observatory with the constancy of occurrence on the Observatory, the indicator value (IndVal) after Dufrêne \& Legendre (1997), and the pvalue of IndVal.

\begin{tabular}{lrrc}
\hline Species & Constancy $[\%]$ & IndVal & $\mathrm{p}$ \\
\hline Leucosphaera bainesii & 100 & 0.885 & 0.001 \\
Eragrostis echinochloidea & 98 & 0.882 & 0.001 \\
Aizoon schellenbergii & 96 & 0.841 & 0.001 \\
Eriocephalus luederitzianus & 89 & 0.820 & 0.001 \\
Stipagrostis uniplumis & 85 & 0.791 & 0.001 \\
Pseudogaltonia clavata & 100 & 0.677 & 0.002 \\
Sida ovata & 89 & 0.670 & 0.001 \\
Enneapogon desvauxii & 100 & 0.637 & 0.001 \\
Tribulus zeyheri & 85 & 0.619 & 0.002 \\
Aptosimum cf. lineare & 91 & 0.593 & 0.005 \\
\hline
\end{tabular}


Table 4-3: List of indicator species of Duruchaus Observatory with the constancy of occurrence on the Observatory, the indicator value (IndVal) after DufrêNe \& LEgENDre (1997), and the p-value of IndVal.

\begin{tabular}{|c|c|c|c|}
\hline Species & Constancy $[\%]$ & IndVal & $\mathrm{p}$ \\
\hline Monechma genistifolium & 85 & 0.851 & 0.001 \\
\hline Felicia clavipilosa & 93 & 0.828 & 0.001 \\
\hline Stipagrostis obtusa & 95 & 0.741 & 0.001 \\
\hline Lotononis platycarpa & 82 & 0.678 & 0.023 \\
\hline Indigofera auricoma & 76 & 0.650 & 0.001 \\
\hline Eragrostis nindensis & 87 & 0.650 & 0.001 \\
\hline Polygala leptophylla & 80 & 0.632 & 0.001 \\
\hline Thesium lacinulatum & 61 & 0.608 & 0.001 \\
\hline Stipagrostis ciliata & 74 & 0.583 & 0.001 \\
\hline Melolobium microphyllum & 80 & 0.562 & 0.120 \\
\hline Melolobium adenodes & 55 & 0.554 & 0.001 \\
\hline
\end{tabular}

The $z$-values as the slope between neighbouring scales showed no significant differences between the Observatories (Table 4-4) as well as the mean $z$-values of power-law SARs, which amount to 0.25 on both Observatories. The one-way ANOVA showed a significant decrease of the $z$-values with increasing plot scale $(\mathrm{p}<0.001)$. The Shannon-Index $\mathrm{H}^{\prime}$ of the $100-\mathrm{m}^{2}$ sub-plots on Duruchaus ranged between 3.44 and 0.98 with a mean of 2.26 (Evenness $84.80-39.53$, mean 63.94), on Narais between 3.18 and 1.66 with a mean of 2.53 (Evenness 82.20 - 46.97, mean 71.09). Comparing these values, they were significantly higher for the Narais Observatory than for Duruchaus (Shannon: $\mathrm{p}=0.002$; Evenness: $\mathrm{p}<0.001$ ).

Table 4-4: Average $z$-values of the slope between different spatial scales and significance level of two-samples permutation tests (p-values) $(n=20)$.

\begin{tabular}{lrrl}
\hline & \multicolumn{1}{c}{ Narais } & Duruchaus & $\mathrm{p}$ \\
\hline $0.01-0.1 \mathrm{~m}^{2}$ & 0.33 & 0.37 & 0.246 \\
$0.1-1 \mathrm{~m}^{2}$ & 0.36 & 0.30 & 0.059 \\
$1-10 \mathrm{~m}^{2}$ & 0.30 & 0.27 & 0.064 \\
$10-100 \mathrm{~m}^{2}$ & 0.25 & 0.24 & 0.569 \\
$100-1,000 \mathrm{~m}^{2}$ & 0.22 & 0.24 & 0.447 \\
\hline
\end{tabular}


Most of the tested soil chemical parameters like $\mathrm{pH}$-values, electric conductivity and loss on ignition showed very low but significant variance between the studied Observatories. Only the carbonate content was substantially higher on Duruchaus. The significant differences in the microrelief and soil structure characterized by soil depth and texture were more pronounced (Table 4-5). The soil types of both Observatories were mainly classified as silty sands, in a few cases with a loamy fraction.

Testing the differences of vegetation patterns, especially the cover values of the vegetation and BSCs were significantly higher on Narais, whereas cover of bare soil was higher on Duruchaus. The vegetation height did not differ significantly between the Observatories (Table 4-6).

Table 4-5: Average values of environmental parameters for the Observatories Narais and Duruchaus and significance level of two-samples permutation tests (p-values) $(n=20)$.

\begin{tabular}{lccr}
\hline Parameter & Narais & Duruchaus & \multicolumn{1}{c}{$\mathrm{p}$} \\
\hline Soil depth [cm] & 17.62 & 25.57 & 0.025 \\
$\mathrm{pH}$ in CaCl2 & 7.32 & 7.34 & 0.107 \\
$\mathrm{pH}$ in H2O & 7.64 & 7.75 & $<0.001$ \\
Electric conductivity (EC) & 104.35 & 108.75 & 0.050 \\
Loss on ignition [g] & 0.05 & 0.04 & 0.014 \\
variation of microrelief [cm] & 6.13 & 16.88 & 0.027 \\
Percentage soil skeleton [\%] & 15.63 & 36.52 & $<0.001$ \\
Percentage fine soil [\%] & 84.37 & 63.48 & $<0.001$ \\
$\mathrm{CaCO}_{3}[\%]$ & 2.33 & 13.27 & $<0.001$ \\
\hline
\end{tabular}

Table 4-6: Average values of vegetation parameters for the Observatories Narais and Duruchaus and significance level of two-samples permutation tests (pvalues) $(n=20)$.

\begin{tabular}{lccc}
\hline Parameter & \multicolumn{1}{c}{ Narais } & Duruchaus & \multicolumn{1}{c}{$\mathrm{p}$} \\
\hline Cover total [\%] & 47.00 & 41.77 & 0.023 \\
Cover annuals [\%] & 14.07 & 8.55 & 0.005 \\
Cover perennials [\%] & 39.58 & 31.61 & 0.017 \\
Cover BSC [\%] & 72.75 & 17.06 & $<0.001$ \\
Cover of bare soil [\%] & 8.26 & 14.07 & 0.019 \\
Height total [cm] & 99.88 & 97.25 & 0.865 \\
\hline
\end{tabular}




\subsection{Discussion}

The two Observatories Narais and Duruchaus did not show significantly differences in species richness of most spatial scales despite their differing grazing regime and their clearly separated floristic composition indicated by the indicator species analysis. The higher grazing intensity on the Duruchaus Observatory did not result in lower but even in slightly, yet not significantly higher species richness. TODd \& Hoffman (1999) found the same trend comparing heavily grazed communal to lightly grazed private-owned rangelands in the Nama Karoo of Namaqualand, South Africa. Naveh \& Whittaker (1979), who described a similar pattern in grazed Mediterranean shrublands, explained this 'paradox' with the long evolutionary history of the native species under constant stress by drought, fire and grazing in their studied region. Supporting this thesis, Hiernaux (1998) found most species in the old Sahelian fallows to be evolutionary adapted to grazing. For Southern African savannas, a similar or even longer evolutionary interaction between the vegetation and grazing can be presumed. The savannas of the region have developed since the late Miocene (approximately 10 million years before present) under the constant influence of megaherbivores like elephants, giraffes, and different gazelle species (ScotT et al., 1997).

A frequently cited explanation for differing species richness is the intermediate disturbance hypothesis (Grime, 1973; Connell, 1978). Grazing as a disturbance of the vegetation prevents the dominance of single species and therefore increases plant species richness at an intermediate disturbance level (Olff \& Ritchie, 1998). The low grazing intensity at Narais Observatory could lead to the dominance of certain species (e.g. Eragrotis echinochloidea, Stipagrostis uniblumis) and thus to a lower species richness than at the stronger grazed Duruchaus farm. However, it is questionable how to apply this general hypothesis for a practical comparison of two sites like in this study. At first, the level of disturbance by grazing intensity should be determined. The grazing intensity on Narais is definitely lower than on Duruchaus (HAARMEYER et al., 2010) but it is not a completely abandoned area. Duruchaus is grazed more heavily close to the stocking limit but not exceeding it (HaARmeyer et al., 2010). Thus, probably both Observatories are at an intermediate grazing state; Narais at the lower, Duruchaus at the higher range. Therefore, they do not differ significantly in species richness. 
Another explanation for higher species richness on the more intensive grazed Duruchaus Observatory could be the higher spatial heterogeneity on Duruchaus Observatory (see chapter 3.4.6) indicated by deeper drainage lines and steeper slopes than on Narais (SCHAARESCHLÜTERHOF, 2008). Supplementary, the environmental parameters sampled in this study showed significantly higher geomorphological and soil structural heterogeneity on Duruchaus expressed by maximum variation of relief at the plots, soil depth, and proportion of coarse and fine soil fractions. These parameters have an important influence on soil drainage that could positively influence plant species richness (BURNETT et al., 1998).

These environmental differences also question the comparability of the two Observatories, despite the fact that they are directly adjacent. Although relatively low variability in some soil chemical parameters like $\mathrm{pH}, \mathrm{EC}$, and loss on ignition was determined, which probably does not have any ecological effect on the vegetation, other parameters like carbonate content, relief variation, and soil structure showed remarkable distinctions between the Observatories which can mask effects of the grazing regime. These differentiating parameters are thereby not influenced by the effect of grazing themselves but caused by the general geomorphological and geological preconditions of the area. The special azonal sites distinguishing the two Observatories like pan structures on Narais and deep drainage lines on Duruchaus (HAARMEYER et al., 2010) were not responsible for the generally differing pattern because only very few sampled plots of this study covered these sites.

In contrast to the indication of slightly higher species richness on Duruchaus, the Shannon diversity index and the evenness as additional measures for $\alpha$-diversity were slightly but significantly higher on Narais. Since a higher Shannon index indicates a more evenly abundance of the occurring species, dominance of a few grazing tolerant species can diminish its value. Hiernaux (1998) reported for the Sahel zone that a few species adapted to the extreme level of stress caused by heavy grazing pressure, achieved dominance, and could occur on a large extend. Other species could only grow at special save sites. In this study, species like Melolobium adenodes or Stipagrostis obtusa turned out to dominate on some plots of the Duruchaus Observatory and to inhibit the growth of other species but the Observatory provides enough save sites for more grazing sensitive species on account of its spatial heterogeneity so that no reduction of the total species richness took place. 
The $z$-values as measurements for $\beta$-diversity showed no significant difference between the two Observatories, neither if they were calculated as the slope of line between sequent plot sizes in double-logarithmic space nor as the exponent of the power-law SARs. The significantly decreasing $z$-values of neighbouring scale sizes with increasing plot scale could be explained by the simple reason that most of the common and high abundant species were already found in the smaller plots so that only a few scarcer species added up to the species richness at larger plot scales. De BeLLo et al. (2007) could not find an interaction of $z$-value between different spatial scales to grazing intensity as well.

The reduced vegetation and BSC cover on Duruchaus could be explained by the higher grazing intensity which was also stated in most other related studies (Greatz \& Tongway, 1986; Todd \& Hoffman, 1999; Ponzetti \& McCune, 2001, de Bello et al., 2007). Defoliation by grazing and trampling are a severe disturbance for plants and BSCs and cannot be compensated under the unfavourable semi-arid climate conditions. The differing cover of vegetation and BSCs is also responsible for the clearly visible fence line contrast. The difference was strongest for bare soil and BSC cover. A similar pattern was reported in a study by Greatz \& Tongway (1986) who studied a fence line contrast in rangelands in southern Australia. They stated that especially BSCs were highly impacted by grazing. Interestingly, the total maximal height of the vegetation did not significantly differ between the Observatories, which is in line with the findings of ECCARD et al. (2000) in a study in the Nama Karoo biome. A possible reason for this observation could be the sampling period. In the middle of the rainy season almost all plant species in the region reached their maximal development and growth height. The instantaneous grazing activities had a less pronounced influence in this period than later in the year because an excessive supply of biomass existed for the grazers.

The significantly higher cover values for annual as well as for perennial plant species on Narais indicated a change of species composition, eventually related to the grazing intensity. These results were surprising because other authors described a significant cover shift from long-lived perennials like dwarf shrubs to short-lived and annual grass species under higher grazing pressure in semi-arid rangelands (Todd \& Hoffman, 1999, Naveh \& Whittaker, 1979; Fynn \& O'ConNor, 2000). In this study, I found an increase of perennials and annuals in cover under lower grazing influence, with the increase of perennials being less pronounced than the increase of 
annuals. This observation could be partly explained by the significantly higher total vegetation cover on Narais, which leads also to higher cover values both for annuals and perennials. The unexpected finding about considerably lower cover of annuals on Duruchaus could be caused by the before mentioned dominance of the perennial species Melolobium adenodes and Stipagrostis obtusa. Annual species probably could not compete with these species on a larger extend. More detailed investigations on the individual species level are needed to clarify the role of grazing on the change in species composition.

\subsection{Conclusion}

On the one hand, this study showed a substantial influence of differing grazing regimes of the Observatories on plant diversity patterns. Especially the species composition and the vegetation and BSCs cover differed strongly between the two Observatories whereas the species richness showed surprisingly similar values. On the other hand, it questioned the suitability of the two Observatories Narais and Duruchaus for statistical comparison of the areas by grazing impact because of the determined variability of other ecological factors, particularly of the microrelief and soil parameters. 


\section{Effects of sampling time effort on completeness of vegetation surveys in a semi-arid savanna ecosystem in central Namibia}

\subsection{Introduction}

Many plant diversity studies and monitoring programs use plot-based sampling schemes. The selection of appropriate plot size and shape (Shmida, 1984; PeEt et al., 1998; Dengler, 2009a) depends on the requirements to answer the specific research question with highest accuracy, on the one hand, and on the time and personnel resources of the project on the other. Under these circumstances, there always has to be found a compromise between high ambitions and limited funding (VITTOZ \& Guisan, 2007).

In studies using a nested plot design like the Whittaker (SHMIDA, 1984) or Modified-Whittaker plots (Stohlgren et al., 1995), the North Carolina Vegetation Survey protocol (Peet et al., 1998), the BIOTA biodiversity monitoring scheme (Jürgens et al., submitted), or the flexible multi-scale approach by Dengler (2009a) the sampled scales mostly range from $0.01 \mathrm{~m}^{2}$ to 1,000 $\mathrm{m}^{2}$. At these scales nearly complete sampling of plant species seem to be achievable with reasonable resources. However, some authors tested the influence of time effort and number of observers on completeness and accuracy of vegetation surveys in this scale range and found a rather high discrepancy between records of different observers, divergent time effort and estimated 'true' species richness of the plots (NiLsson \& Nilsson, 1985; Lepš \& Hadincova, 1992; Klimeš et al, 2001; Archaux et al., 2006, 2009). They highlighted the need of awareness for insufficient sampling methodology when comparing results within and between studies. On the floristic level, typically rare, low growing, or underdeveloped individuals and species are not identified or misidentified (ARCHAUX et al., 2009).

I conducted this study within the BIOTA southern Africa monitoring program (JÜRGENS et al., submitted). This program established Observatories of $1-\mathrm{km}^{2}$ scale in Namibia and South Africa. The Observatories are divided into 100 1-ha grid cells of which 20 were monitored in regards to the vegetation every year since 2005 . The project used a nested plot design including scales of 100 $\mathrm{m}^{2}(10 \mathrm{~m} \times 10 \mathrm{~m}), 1,000 \mathrm{~m}^{2}(20 \mathrm{~m} \times 50 \mathrm{~m})$ and in addition an exceptionally large one of 10,000 $\mathrm{m}^{2}(100 \mathrm{~m} \times 100 \mathrm{~m})$ (HAARMEYER et al., 2010). Because of lacking time resources, the observers could normally spend only around 15-30 minutes on the largest plot (Wesuls, personal 
communication, 2010). It is questionable whether a comprehensive species inventory can be achieved with such a low investment of sampling time.

In order to figure out the discrepancy between the results of the samples in the BIOTA program and 'true' species richness, I conducted an additional vegetation survey at ten exemplary 1-ha plots of the BIOTA monitoring scheme with a much higher time effort and a standardized sampling method. Because I was aware of the fact that it is nearly impossible to achieve a complete species list within my sampling time frame as well as with the BIOTA data set, I estimated the 'true' species richness at these plots with asymptotic models. With these estimates, I determined the level of exhaustiveness (ARCHAux et al., 2006) after a defined sampling time. This procedure aimed at providing information on an appropriate sampling time effort to record a majority of species for these large plot size in a semi-arid savanna ecosystem. With this information, I evaluated the reliability of the collected data on the studied Observatories in the BIOTA program. Comparing the species records of this study with the species list of the BIOTA monitoring, I analysed which kind of species tend to be overlooked in this savanna ecosystem.

\subsection{Methods}

\subsubsection{Field methods}

On ten 1-ha plots, I investigated the vegetation with an additional sampling method, in the following text named as 'extensive sampling'. I fitted the plots into the BIOTA biodiversity monitoring scheme (JÜRGENS et al., submitted) using the GPS-measured ha-grid cells of the two Observatories Narais and Duruchaus. I chose cells that have been sampled within the yearly BIOTA vegetation monitoring from 2005 to 2009 and furthermore included the $1,000-\mathrm{m}^{2}$ plots of my general study (see chapter 2.6). Following this selection method, I determined three 1-ha plots on the Narais Observatory (ha-codes N-08, N-38, and N-91) and seven on the Duruchaus Observatory (D-06, D-24, D-51, D-63, D-67, D-74, and D-82). In the BIOTA monitoring scheme, all vascular plants were recorded by experienced botanists on the 1-ha plot scale as well but with much less time effort (approximately 15 - 30 minutes per plot).

I started the vegetation sampling from the north-western edges of the plots by first noting all recognizable species from this point. The elapsed time of this procedure, I stopped on a stop watch. Then I started to walk over the plot in regular loops sampling all vascular plant taxa and 
noting the point of time when I found a new one. Additively, I logged my track on the handheld GPS device. Except for plots D-63 and D-74, I recorded the total sampling effort in time and walked distance. Total time effort was not a priori limited and varied due to different species richness and habitat heterogeneity.

\subsubsection{Data analysis}

For each plot, I determined the sampled species richness of the extensive sampling, of the records of the BIOTA monitoring scheme on the same plots in 2009, and of the combined BIOTA records over the years 2005-2009. Further, I developed a method to estimate a reliable 'true' species richness of each plot. For this purpose, I plotted the species number to every corresponding second of sampling effort for each of the 1-ha plots. I used every second of the sampling time and not only the recorded points in time at which I found new species in order not to create a bias to the left-hand end of the curve. I assumed this bias due to the reason that I found more species per time unit in the beginning than in the later sampling period. To the resulting relationships, I fitted different asymptotic models that are commonly used for SAR- and SSR-analyses namely logistic, rational, asymptotic regression, Michaelis-Menten (Monod), and Lomolino function (Table 5-1) with the non-linear least-square method (function 'nls' in $\mathrm{R}$ (R Development Core Team, 2008)). Fitting asymptotic functions to species-sampling effort relationships and determining their saturation level is an appropriate method for estimating species richness for plots of a defined area (Colwell \& Coddington, 1994; Gotelli \& Colwell, 2001; Dengler, 2009b).

Table 5-1: Overview of asymptotic functions used to fit the species-sampling effort relationship.

\begin{tabular}{|c|c|c|c|c|}
\hline No. & Model name & Model & Parameters & Source \\
\hline 1 & $\begin{array}{l}\text { Michaelis-Menten } \\
\text { (Monod) function }\end{array}$ & $S=b_{0} A /\left(b_{1}+A\right)$ & 2 & $\begin{array}{l}\text { TJøRVE (2003), } \\
\text { KLUTH \& } \\
\text { BRUELHEIDE (2004) }\end{array}$ \\
\hline 2 & $\begin{array}{l}\text { Negative exponential } \\
\text { function }\end{array}$ & $S=b_{0}\left(1-\exp \left(-b_{1} A\right)\right)$ & 2 & TJøRVE (2003) \\
\hline 3 & Rational function & $S=\left(b_{0}+b_{1} A\right) /\left(1+b_{2} A\right)$ & 3 & TJøRVE (2003) \\
\hline 4 & Logistic function & $S=b_{0} /\left(1+\exp \left(-b_{1} A+b_{2}\right)\right)$ & 3 & TJøRVE (2003) \\
\hline 5 & Lomolino function & $S=b_{0} /\left(1+\left(b_{1}^{\log \left(b_{2} / A\right)}\right)\right)$ & 3 & $\begin{array}{l}\text { Lomolino (2000), } \\
\text { TJøRVE (2003) }\end{array}$ \\
\hline 6 & $\begin{array}{l}\text { Asymptotic regression } \\
\text { function }\end{array}$ & $S=b_{0}-b_{1} b_{2}^{-A}$ & 3 & TJøRVE (2003) \\
\hline
\end{tabular}


I determined the $\triangle \mathrm{AICc}$ scores of the models with the log-likelihood method (BURNHAM \& Anderson, 2004) employing the function 'selMod' in package 'pgirmess' (Giraudoux, 2008) in R (R Development Core Team, 2008). As a second goodness-of-fit metric for the applied models, I calculated their log error of extrapolation (LEE) (DENGLER, 2009b). For LEE, I omitted the time span larger than one-tenth of the total sampling time and recomputed the same models with the reduced data set. With the resulting model parameters, I extrapolated the species richness to the total time effort and calculated the deviation between this estimate and the actually observed species richness on the $\log (\mathrm{S})$-scale. I ranked the models after their $\triangle \mathrm{AICc}$ and LEE scores (closest to 0) for each plot and averaged the two ranks afterwards. For the best fitting model, I determined the asymptotic level which I stated to be equivalent to the expected saturation of species richness at the plots.

In order to give information on the extensiveness of the vegetation sampling conducted in this and the BIOTA study after a given time span, I used the richness estimation of the saturation function to determine a level of estimated exhaustiveness. The level of exhaustiveness as the ratio between recorded and 'true' or estimated species richness per plot for a given time effort serves as an instrument to determine the completeness of vegetation surveys (ArCHAUX et al., 2006). ArChaux (2006) introduced this concept using a second-order Jackknife richness estimator to determine the 'true' richness; in other studies (NiLsson \& NiLsson, 1985; KLIMEš et al., 2001) the 'true' species richness was based directly on field data. Keeping this difference in mind, the term 'level of exhaustiveness' is used synonymously to 'level of estimated exhaustiveness' in this study. Thus, I was able to standardize the proportion of species recorded with a specific time effort for the sampled plots.

Additionally, I compared my species list with the one of the BIOTA program sampled in the same year 2009 and the accumulated list from 2005 till 2009 at the species level to find out which species were frequently neglected by lower sampling effort and whether they shared certain characteristics. For this purpose, I took into account plant functional traits like life form and life duration cycle, retrieved from the annotated plant checklists of Craven (1999) and Germishuizen \& MEYER (2003). 


\subsection{Results}

\subsubsection{Sampling results}

Sampling the 1-ha plots required $113 \mathrm{~min}( \pm 20.29 \mathrm{SD})$ and $4067.5 \mathrm{~m}( \pm 497.26 \mathrm{SD})$ walked track on average. The time effort to sample the plots ranged from 82 to $136 \mathrm{~min}$, the walked distance from 3390 to $5000 \mathrm{~m}$. At all 1-ha plots together, I found 145 vascular plant species with the extensive sampling, 79 species $( \pm 13.83 \mathrm{SD})$ per plot in average, ranging from 60 to 100 species. In the BIOTA monitoring scheme, 144 species were recorded from 2005 till 2009 at the same 1-ha plots, 115 species only in 2009. The average species richness per plot amounted to 71 species $( \pm 7.44 \mathrm{SD})$ for the cumulated data set, to 56 species $( \pm 6.41 \mathrm{SD})$ in 2009 . On average, only $72 \%( \pm 11.81 \mathrm{SD})$ of the species richness recorded by the extensive sampling was sampled in the BIOTA monitoring in the same year 2009. In the cumulated BIOTA monitoring, $91 \%( \pm$ 14.10 SD) of the species richness of the extensive sampling 2009 was recorded on average. Only in two plots (D-63, D-74), more species were noted in the cumulated BIOTA sampling than in the extensive sampling (Figure 5-1).

\subsubsection{Model selection and saturation level}

The best model according to the mean $\triangle \mathrm{AICc}$ rank was the Lomolino function (1.2) followed by rational function (1.8). For nine of the ten plots the Lomolino function was the best performing model and the rational function the second best. Only in one case they changed place in the ranking. According to the mean LEE rank, the Michaelis-Menten function (2.1) performed best directly followed by rational and Lomolino function (both 2.2). All other models performed worse (Table 5-2).

Table 5-2: Ranking and mean saturation level of applied saturation models according to the goodness-of-fit measurements $\triangle \mathrm{AICc}$ and LEE.

\begin{tabular}{lcccccc}
\hline & $\begin{array}{l}\text { Michaelis- } \\
\text { Menten }\end{array}$ & $\begin{array}{l}\text { Negative } \\
\text { exponential }\end{array}$ & Rational & Logistic & Asymptotic & Lomolino \\
\hline Rank $\triangle$ AICc & 4.0 & 5.8 & 1.8 & 4.9 & 3.3 & 1.2 \\
Rank LEE & 2.1 & 4.6 & 2.2 & 5.6 & 4.3 & 2.2 \\
Mean rank & 3.1 & 5.2 & 2.0 & 5.3 & 3.8 & 1.7 \\
Saturation & 84.5 & 72.4 & 92.7 & 76.5 & 79.3 & 2862.9 \\
\hline
\end{tabular}


The saturation level, which indicates an estimate for the 'true' species richness at one plot, ranged from 64 to 112 species per ha-plot for the Michaelis-Menten function, similarly from 63 to 129 for the rational function, and between 61 and huge 26117 species for the Lomolino function. The Lomolino function resulted in extreme species richness outliers with more than 300 species per plot for four of the ten sampled plots. Because of these implausible outliers, I did not choose this function for further analysis although it was the best fitting function according to the applied goodness-of-fit measurements. I used the saturation level of the rational function as the secondbest ranked model instead to estimate the total species richness of the studied plots.

The estimates averaged to 93 species $( \pm 21.95$ SD) per plot. Comparing these estimates of species richness of the individual plots with the different sampling approaches, they predicted $16.5 \%$ more species on average than in the extensive sampling, 30.6\% more than in the cumulated BIOTA data set and 65.8\% more than in the BIOTA sampling 2009. For the plots N-38, D-24, D-51, and D-67 estimated figures for species richness were twice as high as recorded in the BIOTA sampling 2009; in plot D-74, the values were almost the same (Figure 5-1).

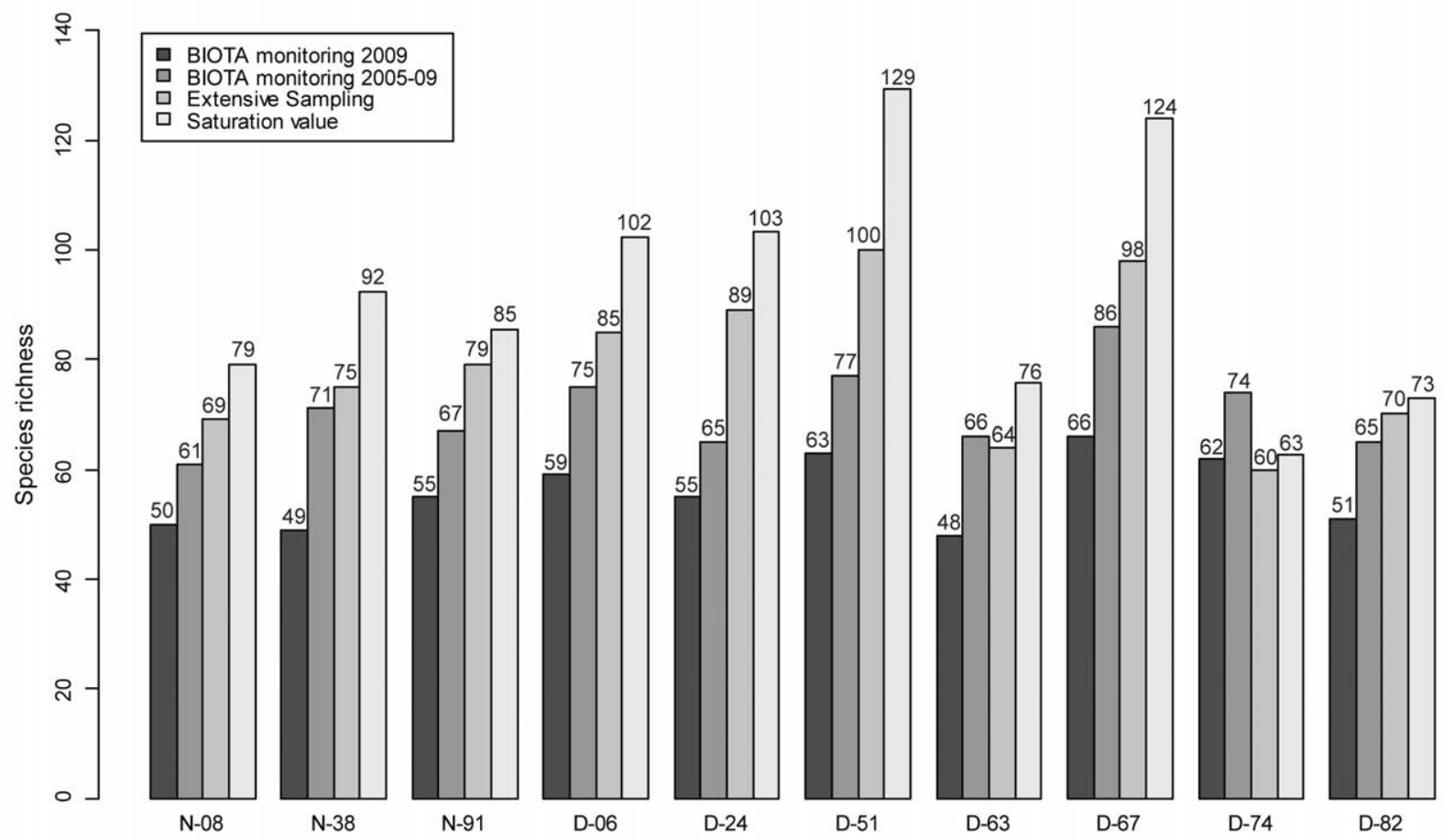

Figure 5-1: Species richness of the sampled 1-ha plots determined in the BIOTA monitoring in 2009, accumulated from 2005 to 2009 in the BIOTA monitoring, with the extensive sampling of this study, and estimated with the saturation value of rational models based on the extensive sampling. 


\subsubsection{Level of exhaustiveness}

With these estimates of 'true' species richness, I calculated the level of exhaustiveness for each plot and mean values for different time spans. The mean level of exhaustiveness ( \pm SD) after 15 min was $0.50( \pm 0.09)$, so half of the species of the plots were found in this time span. After $30 \mathrm{~min}$, a level of $0.61( \pm 0.10)$ was reached, $0.72( \pm 0.10)$ after one hour. After the maximum time effort of most sampled plots $(120 \mathrm{~min})$, the level amounted to 0.85 ( \pm 0.07$)$ (Figure 5-2). The highest level of exhaustiveness was reached for the plot N-91 with 0.94 after 120 min of sampling.

For the cumulated BIOTA richness data of the years 2005-2009 from the same plots, I determined a mean level of exhaustiveness of $0.79( \pm 0.16)$. In 2009 , the mean level of exhaustiveness of the BIOTA monitoring amounted to $0.63( \pm 0.14)$ which would be equivalent to 35 min sampling effort with the sampling strategy of this study.

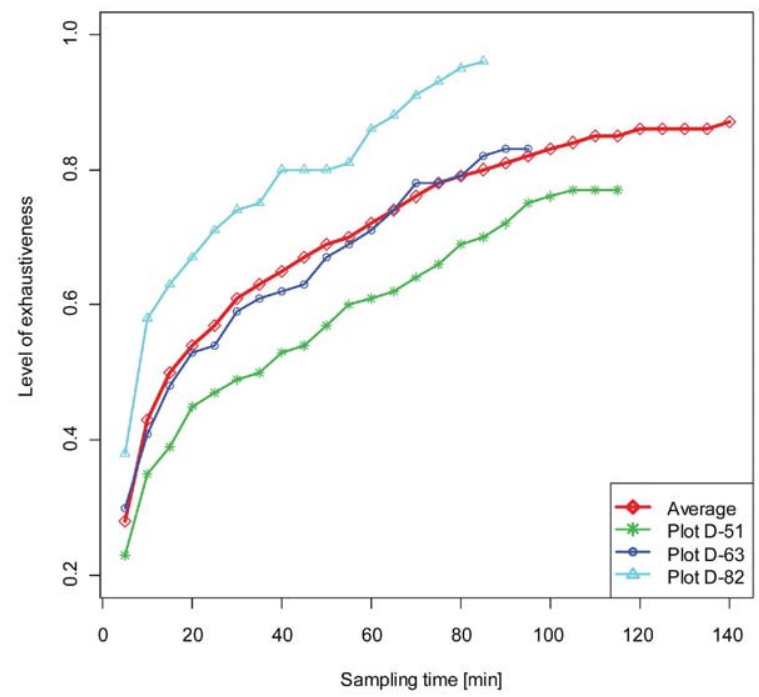

Figure 5-2: Level of exhaustiveness per sampling time effort shown in 5-minutes intervals for the average of ten sampled 1-ha plots and for three exemplary plots of extensive sampling: D-51 exemplifying a species-rich plot with low exhaustiveness, D-63 representing a species-poor plot with intermediate exhaustiveness, and D-82 as similarly species-poor plot but with high exhaustiveness.

\subsubsection{Overlooked plant species}

On the ten 1-ha plots, I found 11 vascular plant species that have never been recorded on these plots in the BIOTA monitoring before. In the year 2009, I recorded 32 species more than in the BIOTA monitoring of the same year; eight species were overlooked in more than $75 \%$ of their plots of occurrence (Table 5-3). These 40 frequently overlooked species can be classified into three main groups: i) rare species that occur only once or twice in my sampling (e.g. Aloe 
littoralis, Cyphostemma hereroense, Hoodia gordonii), ii) annual therophytes and perennial geophytes like Chenopodium amboanum, Limeum aethiopicum, Setaria verticillata, and iii) species characterised by low growth height $(<10 \mathrm{~cm})$ like Hermannia affinis, Limeum aethiopicum, Portulaca kermesina.

\subsection{Discussion}

\subsubsection{Sampling results}

The results in species richness on the sampled 1-ha plots differed considerably between the sampling of this study and of the BIOTA monitoring project. Reason for these differences are the more intensive sampling with higher time effort and the divergent sampling design that was applied in this study. I sampled the species with consistent methodology by walking regular loops over the whole plot area. In the BIOTA sampling design, primarily the 100 - and $1,000-\mathrm{m}^{2}$ subplots in the middle of the 1-ha plots were sampled with high accuracy and time effort (around 120 minutes), and afterwards only few minutes (15-30 minutes) remained to work on the 1-ha scale i.e. on the remaining $9,000 \mathrm{~m}^{2}$ (Jürgens et al., submitted, D. Wesuls, personal communication, 2010). To achieve the best possible success in finding new species within this limited time span, mainly special sites like tree or shrub formations and their understories, where most probably additional species occur, were selectively sampled (D. Wesuls, personal communication, 2010). These differences in the sampling approach give an explanation for the finding that on the one hand less species have been found in the BIOTA monitoring in 2009 but on the other hand the level of exhaustiveness reflects a higher sampling time effort than actually invested.

The higher species richness of this study compared to the accumulated BIOTA data is probably caused by the higher time effort and divergent sampling design as well but could also be abetted by the comparatively very good development of the vegetation mainly because of regular and strong precipitation in the year of study. Under these conditions, also sporadically occurring species could be recorded, and the individuals of most species thrived well and were therefore easier to spot and to identify. The annual monitoring over five years with low sampling effort does not seem to compensate this positive external effect. 
Table 5-3: Table of record frequencies of overlooked vascular plant species at ten sampled 1-ha plots in this study and in the BIOTA monitoring from 2009, their rate of detection, and their plant functional traits. All species for which the BIOTA sampling reported $\leq 25 \%$ of the actual occurrences are shown.

\begin{tabular}{|c|c|c|c|c|c|}
\hline Species & $\begin{array}{l}\text { Extensive } \\
\text { sampling }\end{array}$ & $\begin{array}{c}\text { BIOTA } \\
2009\end{array}$ & $\begin{array}{c}\text { Rate of } \\
\text { detection }\end{array}$ & Life form & $\begin{array}{l}\text { Life duration } \\
\text { cycle }\end{array}$ \\
\hline Aizoon giesii & 8 & 2 & $25 \%$ & Hemicryptophyte & perennial \\
\hline Aizoon virgatum & 4 & 0 & $0 \%$ & Hemicryptophyte & perennial \\
\hline Aloe littoralis & 1 & 0 & $0 \%$ & Micro-Phanerophyte & perennial \\
\hline Amaranthus praetermissus & 4 & 1 & $25 \%$ & Meso-Chamaephyte & perennial \\
\hline Antephora schinzii & 4 & 0 & $0 \%$ & Hemicryptophyte & perennial \\
\hline Aptosimum spinescens & 4 & 1 & $25 \%$ & Nano-Chamaephyte & perennial \\
\hline Aristida meridionalis & 2 & 0 & $0 \%$ & Hemicryptophyte & perennial \\
\hline Blepharis pruinosa & 1 & 0 & $0 \%$ & - & perennial \\
\hline Bulbostylis hispidula & 1 & 0 & $0 \%$ & Hemicryptophyte & perennial \\
\hline Chenopodium amboanum & 8 & 2 & $25 \%$ & Therophyte & annual \\
\hline cf. Cynanchum orangeanum & 4 & 0 & $0 \%$ & Hemicryptophyte & perennial \\
\hline Coccinia rehmannii & 1 & 0 & $0 \%$ & Geophyte & perennial \\
\hline Cucumis africanus & 2 & 0 & $0 \%$ & Geophyte & perennial \\
\hline Cyphostemma hereroense & 1 & 0 & $0 \%$ & Liana & perennial \\
\hline Emilia marlothiana & 3 & 0 & $0 \%$ & - & perennial \\
\hline Eragrostis lehmanniana & 1 & 0 & $0 \%$ & Hemicryptophyte & perennial \\
\hline Eragrostis truncata & 8 & 1 & $12.5 \%$ & Hemicryptophyte & perennial \\
\hline Hermannia affinis & 2 & 0 & $0 \%$ & - & perennial \\
\hline Hermannia cf. fruticulosa & 2 & 0 & $0 \%$ & - & perennial \\
\hline Helichrysum candolleanum & 7 & 0 & $0 \%$ & Meso-Chamaephyte & perennial \\
\hline Hoodia gordonii & 1 & 0 & $0 \%$ & Meso-Chamaephyte & perennial \\
\hline Ipomoea sinensis & 2 & 0 & $0 \%$ & Therophyte & annual \\
\hline Kohautia caespitosa & 1 & 0 & $0 \%$ & Therophyte & annual \\
\hline Launaea intybacea & 5 & 1 & $20 \%$ & - & annual \\
\hline Leucas pechuelii & 3 & 0 & $0 \%$ & Meso-Chamaephyte & perennial \\
\hline Limeum aethiopicum & 9 & 2 & $0 \%$ & Micro-P & perennial \\
\hline Monsonia angustifolia & 1 & 0 & $0 \%$ & Therophyte & annual \\
\hline Nelsia quadrangula & 3 & 0 & $22.2 \%$ & Hemicryptophyte & biennal \\
\hline Ocimum americanum & 4 & 0 & $0 \%$ & Hemicryptophyte & perennial \\
\hline Osteospermum microcarpum & 1 & 0 & $0 \%$ & Hemicryptophyte & perennial \\
\hline Pechuel-loeschea leubnitziae & 1 & 0 & $0 \%$ & Nano-Chamaephyte & perennial \\
\hline Pogonarthria fleckii & 6 & 0 & $0 \%$ & Therophyte & annual \\
\hline Pollichia campestris & 2 & 0 & $0 \%$ & Meso-Chamaephyte & perennial \\
\hline Portulaca kermesina & 1 & 0 & $0 \%$ & Meso-Chamaephyte & perennial \\
\hline Ruelliopsis damarensis & 2 & 0 & $0 \%$ & Hemicryptophyte & perennial \\
\hline Salsola sp. & 1 & 0 & $0 \%$ & Meso-Chamaephyte & perennial \\
\hline Setaria verticillata & 4 & 1 & $25 \%$ & Therophyte & annual \\
\hline Sida cordifolia & 1 & 0 & $0 \%$ & Therophyte & annual \\
\hline Tagetes minuta & 1 & 0 & $0 \%$ & Therophyte & annual \\
\hline Tetragonia calycina & 1 & 0 & $0 \%$ & Therophyte & perennial \\
\hline
\end{tabular}




\subsubsection{Model selection}

Like some other studies (NiLSSON \& Nilsson, 1985; KLImeŠ et al, 2001; ArChauX et al., 2006), I found strong evidence for a curvilinear relationship between sampling time effort and species records that can be described appropriately by the same asymptotic models which are often used to fit SSRs of a defined area (e.g. Dengler, 2009b). This finding was not surprising because a close linear dependency between sampling time and sampled area has to be assumed (ARCHAUX et al., 2006).

The best performing model according to the applied goodness-of-fit measurements was the Lomolino function but its saturation level as estimate for species richness resulted in unrealistic outliers for nearly half of all plots. For both Observatories, the totally recorded species richness of this study accumulated with the observed species from the BIOTA monitoring scheme sampled between 2005 and 2009 amounted to 261 plant species (see chapter 3.3.1). Therefore, an estimated species richness of 300 species and higher per 1-ha plot could not be accepted as a plausible estimation. A reason for the good performance of the Lomolino function could be the high flexibility of this sigmoid asymptotic model with three parameters to well fit all kinds of data sets (Gentile \& Argano, 2005; Dengler, 2008; Dengler \& Boch, 2008). Tjørve (2003) stated that 'the better fit of sigmoid curves does not necessarily prove sigmoid relationships'. I found no statistical tool to penalize this opportunistic behaviour. To avoid wrong conclusions of the further calculations with the help of excessive richness estimates, I performed the further calculations, especially of the level of exhaustiveness, with the second-best performing rational model, which provided more plausible richness estimates.

\subsubsection{Level of exhaustiveness}

For the level of exhaustiveness, ARCHAux (2006) reported $20-30 \%$ of undetected species after

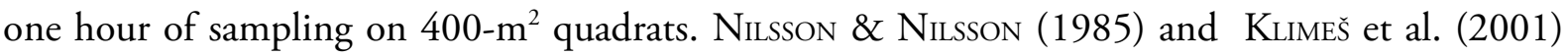
found similar percentages of exhaustiveness in their studies. I determined a level of exhaustiveness at the lower margin of this range after the given time span of one hour although the other mentioned studies are hardly comparable to this one. All of them were performed in central European vegetation types like semi-natural grasslands, deciduous forests, or alpine meadows (Kuimeš et al. 2001; Archaux, 2006; Vittoz \& Guisan, 2007). No study referring to a similar semi-arid ecosystem and to similar plot sizes exists and - as VitToz \& GUISAn (2007) already 
pointed out - 'the influence of vegetation type and plot size on reliability should be further examined with supplementary plots in different vegetation types'. DoLNIK (2003) compared the respective time effort of a complete vegetation survey in 13 European vegetation types. He sampled all vascular plants, bryophytes, and lichens with a nested plot design of 16 subplots from $0.0001 \mathrm{~m}^{2}$ to $900 \mathrm{~m}^{2}$. His time effort for the $900-\mathrm{m}^{2}$ plots ranged from $0.4 \mathrm{~h}$ in a species-poor Corispermum intermedium-Ammophila arenaria community to $14 \mathrm{~h}$ in a structure-rich Melampyrum pratense-Betula pendula community. Compared to the extensive sampling of this study, he invested much more time in most of the studied vegetation types. This higher sampling effort could be caused by the difficulties to find all bryophytes and lichens and to sample all smaller subplots. Another explanation could be seen in the considerably denser and species-richer vegetation in most of these types, e.g. in forest or forest edge habitats. Under these conditions, more species can be hidden by others, and higher time effort is needed to find them. On the other hand, the main plot of $900 \mathrm{~m}^{2}$ is much smaller than the 1-ha plots of this study. Most closely comparable to the semi-arid savanna vegetation on the studied Observatories Narais and Duruchaus were probably the grassland vegetation types with or without shrubs for which DolNik (2003) reported five to seven hours of sampling effort. With a time effort of only two hours at most of the 1-ha plots, a level of exhaustiveness of $85 \%$ seems to be a reasonable result. These considerations additionally support the reliability of the richness estimation with a rational model on which the level of estimated exhaustiveness was based.

The level of exhaustiveness of the cumulated BIOTA data set amounting to 79\% was a little bit lower but still at the upper margin of exhaustiveness compared with other vegetation survey studies (ARCHAUX , 2006). In contrast, the exhaustiveness of the BIOTA sampling from only one year (2009), in which almost $40 \%$ of the estimated species total were not recorded, was quite poor even though the climatic conditions were remarkably good for the development of plant life in the year of study. The sampling time effort of that sampling, which related to only 35 minutes based on the sampling strategy of this study, was clearly insufficient for the detection of an adequate proportion of plant species at the 1-h plots, which supports the assumption made by SCHMiedel et al. (2010). 


\subsubsection{Overlooked plant species}

At the species level, I distinguished three main groups of frequently overlooked species; i) rare species that occurred only once or twice in my sampling and are therefore more likely to be missed with lower sampling effort, ii) annual therophytes and perennial geophytes that grow sporadically in time and space under specific favourable conditions like adequate rainfall and show typically low growth height, and iii) species generally characterised by low growth height which are difficult to find, especially if they grow at sheltered sites e.g. under trees and bushes. The first group i) could be subdivided into two subgroups, one containing species that are rare in individuals and the other species which have low cover values but are not rare in the original sense. For the latter group, ARCHAux (2006) found that all high-covering species were already recorded within the first five minutes of the sampling but most of the species with $r$ or + on the Braun-Blanquet cover-abundance classes were not recorded until close to the end of sampling time. Lepš \& Hadincova (1992) and Vittoz \& Guisan (2007) reported that most of the overlooked species had low cover values. With the extensive sampling methodology of this study, most of this species could be encountered, whereas the 'opportunistic' sampling of the BIOTA monitoring missed them, especially if they grew in the open vegetation and not at special sites.

For the species of the second main group ii), the probability of record increased with higher number of sampled years on the same plots since some of these therophytes and geophytes probably did not occur in every year, especially under highly variable climatic conditions as in the study area (HaARMEYER et al., 2010). Their occurrence mainly depends on the amount and allocation of precipitation during the rainy season. The majority of these species was included in the accumulated BIOTA species list for the years 2005-2009 but not in the list from the BIOTA sampling of one year only. In the year of the study, an exceptional great number of these sporadic species has been recorded by the extensive sampling because of the excellent rainfall conditions during the rainy season 2009 .

\subsection{Conclusion}

In conclusion, this study showed that the vegetation sampling effort within the BIOTA monitoring program on the 1-ha plots was not sufficient to provide reliable plant species richness figures for the Observatories Narais and Duruchaus. Mainly rare, short-living, or low-growing species were overlooked during the sampling. Thus, I advise to use the cumulative data of the 
BIOTA monitoring gathered over several years only with caution for further analyses of the plant diversity at the 1-ha scale of the Observatories. The application of asymptotic models as richness estimators based on the extensive sampling of this study resulted in robust estimates which were suitable to analyse the exhaustiveness of the different sampling approaches within this study. The level of exhaustiveness proved to be a helpful instrument to achieve information about the reliability of vegetation surveys and to provide comparability to similar studies. 


\section{Acknowledgements}

Special thanks go to my supervisors Dr. Jürgen Dengler and Prof. Dr. Michael Manthey, with whom I developed the ideas for this study and who helped me with my work when- and wherever they could. Dirk Wesuls helped me during the adventurous field trip in the savannas of central Namibia and introduced me to the marvellous plant life of the region. Magdalena Pellowski supported me with her mental and practical assistance during the field work. I thank all colleagues of the BIOTA Southern Africa project at the University of Hamburg for their support of my thesis with plenty of constructive advices and comments. The German Federal Ministry for Education and Research (BMBF) financed the field work of this study in the frame of the BIOTA project.

Furthermore, I have to thank the farmers of Narais and Duruchaus, Mrs. Nack and Mr. Olivier, for the possibility dedicated to stay and to work on their lands, and all lovely people who hosted me during my time in Hamburg to work on this thesis. Ronald Kruwinus, Johannes Limberg, Florian Peters, Hille Schlöder, and all unforgotten friends provided invaluable support by proofreading this thesis and giving helpful hints.

This thesis would never have been possible without my parents Sabine Huhle-Peters and Udo Peters supporting all my plans and studies in any situation of my life. 


\section{References}

Ad-hoc-Arbeitsgruppe Boden (2005) Bodenkundliche Kartieranleitung (KA5), Hrsg.: Bundesanstalt für Geowissenschaften und Rohstoffe in Zusammenarbeit mit den Staatlichen Geologischen Diensten, 5. Aufl., Hannover.

Akaike, H. (1978) A Bayesian analysis of the minimum AIC procedure. Annals of the Institute of Statistical Mathematics, 30, 9-14.

Akaike, H. (1979) A Bayesian extension of the minimum AIC procedure of autoregressive model fitting. Biometrika, 66, 237-242.

Archaux, F.; Gosselin, F.; Bergès L. \& Chevalier, R. (2006) Effects of sampling time, species richness and observer on the exhaustiveness of plant censuses. Journal of Vegetation Science, 17, 299-306.

Archaux, F. (2009) Could we obtain better estimates of plot species richness from multiple-observer plant censuses? Journal of Vegetation Science, 20, 603-611.

Arrhenius, O. (1921) Species and Area. Journal of Ecology, 9: 95-99.

Balmford, A.; Bennun, L; ten Brink, B.; Cooper, D.; Côté, I.M.; Crane, P.; Dobson, A.; Dudley, N.; Dutton, I.; Green, R.E.; Gregory, R.D.; Harrison, J.; Kennedy, E.T.; Kremen, C.; Leader-Williams, N.; Lovejoy, T.E.; Mace, G.; May, R.; Mayaux, P.; Morling, P.; Phillips, J.; Redford, K.; Taylor, H.; Ricketts, T.H.; Rodríguez, J.P.; Sanjayan, M.; Schei, P. J.; van Jaarsveld, A.S. \& Walther, B.A.(2005) The Convention on Biological Diversity's 2010 target. Science, 307, 212-213.

Burnham, K.P. \& Overton, W.S. (1979) Robust Estimation of Population Size When Capture Probabilities Vary Among Animals. Ecology, 60, 927-936.

Burnham, K.P. \& Anderson, D.R. (2002) Model selection and multimodel inference - a practical information-theoretic approach. 3rd edn. Springer, New York.

Burnett, M.R.; August, P.V.; Brown, J.H. Jr \& Killingbeck, K.T. (1998) The influence of geomorphological heterogeneity on biodiversity. I. A patch scale perspective. Conservation Biology, 12, 363-370.

Chao, A. (1984) Nonparametric estimation of the number of classes in a population. Scandinavian Journal of Statistics, 11, 265-270.

Chao, A. (1987) Estimating the Population Size for Capture-Recapture Data with Unequal Catchability. Biometrics, 43, 783-791

Chazdon, R.L.; Colwell, R.K.; Denslow, J.S. \& Guariguata, M.R. (1998) Statistical methods for estimating species richness of woody regeneration in primary and secondary rain forests of NE Costa Rica. In: Dallmeier, F. \& Comiskey, J. (eds). (1998) Forest Biodiversity Research, Monitoring and Modeling: Conceptual Background and Old World Case Studies. Parthenon Publishing, Paris, pp. 285-309. 
Chiarucci, A.; Maccherini, S. \& De Dominicis, V. (2001) Evaluation and monitoring of the flora in a nature reserve by estimation methods. Biological Conservation, 101, 305-314.

Chiarucci, A.; Enright, N.J.; Perry, G.L.W.; Miller, B.P. \& Lamont, B.B. (2003) Performance of nonparametric species richness estimators in a high diversity plant community. Diversity and Distributions, 9, 283-295.

Chiarucci, A.; Viciani, D.; Winter, C. \& Diekmann, M. (2006) Effects of productivity on species-area curves in herbaceous vegetation: evidence from experimental and observational data. Oikos, 115, 475-483.

Chiarrucci, A. \& M.W. Palmer (2006) The inventory and estimation of plant species richness. Encyclopedia of Life Support Systems (EOLSS) [http://www.eolss.net]. EOLSS Publishers, Oxford.

Cohen, A.C.J. (1959) Simplified estimators for the normal distribution when samples are singly censored or truncated. Technometrics, 1, 217-237.

Colwell, R.K. \& Coddington, J.A. (1994) Estimating terrestrial biodiversity through extrapolation. Philosophical Transactions of the Royal Society Series B: Biological Sciences, 345, 101-118.

Colwell, R.K.; Mao, C. X. \& Chang, J. (2004) Interpolating, extrapolating, and comparing incidence based species accumulation curves. Ecology, 85, 2717-2727.

Colwell, R. K. (2009) EstimateS: Statistical estimation of species richness and shared species from samples. Version 8.2. User's Guide and application published at: http://purl.oclc.org/estimates.

Condit, R.; Hubbell, S.P.; LaFrankie, J. V.; Sukumar, R.; Manokaran, N.; Foster, R.B. \& P.S. Ashton 1996. Species-area and species-individual relationships for tropical trees: a comparison of three 50-ha plots. Journal of Ecology, 84, 549-562.

Connell, J.H. (1978) Diversity in tropical rain forests and coral reefs. Science, 199, 1302-1303.

Connor, E.F. \& McCoy, E.D. (1979) The statistics and biology of the species-area relationship. The American Naturalist, 113, 791-833.

Craven, P. (ed.) (1999) A checklist of Namibian plant species. Southern African Botanical Diversity Network Report No. 7.

De Bello, F.; Lepš, J. \& Sebastià, M.T. (2007) Grazing effects on the species-area relationship: variation along a climatic gradient in NE Spain. Journal of Vegetation Science, 18, 25-34.

Dengler, J. (2008) Pitfalls in small-scale species-area sampling and analysis. Folia Geobotanica, 43, 269-287.

Dengler, J. (2009a) A flexible multi-scale approach for standardized recording of plant species richness patterns. Ecological Indicators, 9, 1169-1178.

Dengler, J. (2009b) Which function describes the species-area relationship best? A review and empirical evaluation. Journal of Biogeography, 36, 728-744. 
Dengler, J. \& Boch, S. (2008) Sampling-design effects on properties of species-area curves - a case study from Estonian dry grassland communities. Folia Geobotanica, 43, 289-304.

Dengler, J. \& J. Oldeland (2010) Effects of sampling protocol on the shapes of species richness curves. Journal of Biogeography, 37, 1698-1705.

Deutsches Institut für Normung (DIN) (1997) DIN 19684-5. Chemische Laboruntersuchungen, Bestimmung des Carbonatgehaltes im Boden (Chemical analysis, determination of soil carbonate content). Berlin, Köln.

Dolnik, C. (2003) Artenzahl-Areal-Beziehungen von Wald- und Offenlandgesellschaften - Ein Beitrag zur Erfassung der botanischen Artenvielfalt unter besonderer Berücksichtigung der Flechten und Moose am Beispiel des Nationalparks Kurische Nehrung (Russland). Mitt. Arbeitsgem. Geobot. Schleswig-Holstein Hamb. Kiel. 62, pp.183.

Dufour, A.; Gadallah, F.; Wagner, H.H.; Guisan, A. \& Buttler, A. (2006) Plant species richness and environmental heterogeneity in a mountain landscape: effects of variability and spatial configuration. Ecography, 29, 573-584.

Dufrêne, M. \& Legendre, P. (1997) Species assemblages and indicator species: the need for a flexible assymetrcal approach. Ecological Monographs, 67, 345-366.

Eccard, J.A.; Walther, R.B. \& Milton, S.J. (2000): How livestock grazing affects vegetation structures and small mammal distribution in the semi-arid Karoo. Journal of Arid Environments, 46, 103-106.

Facelli, J.M. \& Springbett, H. (2009) Why do some species in arid lands increase under grazing? Mechanisms that favour increased abundance of Maireana pyramidata in overgrazed chenopod shrublands of South Australia. Austral Ecology, 34, 588-597.

Flather, C.H. (1996) Fitting species-accumulation functions and assessing regional land use impacts on avian diversity. Journal of Biogeography, 23, 155-168.

Fridley, J.D.; Peet, R.K.; Wentworth, T.R. \& White, P.S. (2005) Connecting fine- and broadscale species-area relationships of southeastern U.S. flora. Ecology, 86, 1172-1177.

Fynn, R.W.S. \& O'Connor, T.G. (2000) Effect of Stocking Rate and Rainfall on Rangeland Dynamics and Cattle Performance in a Semi-Arid Savanna, South Africa. Journal of Applied Ecology, 37, 491-507.

Gaston, K.J. (1996) Species richness: measure and measurement. In: Gaston, K.J. (ed.), Biodiversity. A Biology of Numbers and Differences. Blackwell Science, Cambridge, pp. 77113.

Gaston, K.J. (2000) Global patterns in biodiversity. Nature, 405, 220-227.

Gaston, K.J. \& Spicer, J.I. (2004) Biodiversity. An Introduction. Blackwell Publishing, Oxford.

Gentile, G. \& Argano, R. (2005) Island biogeography of the Mediterranean Sea: the species-area relationship for terrestrial isopods. Journal of Biogeography, 32, 1715-1726. 
Germishuizen, G. \& Meyer, N.L. (eds) (2003) Plants of southern Africa: an annotated checklist. Strelitzia, 14, 1-1231.

Giraudoux, P. (2008): Pgirmess: Data Analysis in Ecology. R package version 1.3.7. http://perso.orange.fr/giraudoux/SiteGiraudoux.html.

Gitay, H.; Roxburgh, S.H. \& Wilson, J.B. (1991) Species-area relations in a New Zealand tussock grassland, with implications for nature reserve design and for community structure. Journal of Vegetation Science, 2, 113-118.

Gleason, H.A. (1922) On the relation between species and area. Ecology, 3, 158-162.

Gotelli, N.J. \& Colwell, R.K. (2001) Quantifying biodiversity: procedures and pitfalls in the measurement and comparison of species richness. Ecology Letters, 4, 379-391.

Greatz, R.D. \& Tongway, D.J. (1986) Influence of grazing management on vegetation, soil structure and nutrient distribution and the infiltration of applied rainfall in a semi-arid chenopod shrubland. Australian Journal of Ecology, 11, 347-360.

Gray, J.S., Ugland, K.I. \& Lambshead, J. (2004) Species accumulation and species area curves - a comment on Scheiner (2003). Global Ecology and Biogeography, 13, 469- 476.

Grime, J. P. (1973) Competitive exclusion in herbaceous vegetation. Nature, 242, 344-347.

Haarmeyer, D.H.; Luther-Mosebach, J.; Dengler, J.; Schmiedel, U.; Finckh, M.; Berger, K.; Deckert, J.; Domptail, S.E.; Dreber, N.; Gibreel, T.; Grohmann, C.; Gröngröft, A.; Haensler, A.; Hanke, W.; Hoffmann, A.; Husted, L.B.; Kangombe, F.N.; Keil, M.; Krug, C.B.; Labitzky, T.; Linke, T.; Mager, D.; Mey, W.; Muche, G.; Naumann, C.; Pellowski, M.; Powrie, L.W.; Pröpper, M.; Rutherford, M.C.; Schneiderat, U.; Strohbach, B.J.; Vohland, K.; Weber, B.; Wesuls, D.; Wisch, U.; Zedda, L.; Büdel, B.; Darienko, T.; Deutschewitz, K.; Dojani,S.; Erb, E.; Falk, T.; Friedl, T.; Kanzler, S.-E.; Limpricht, C.; Linsenmair, K.E.; Mohr, K.; Oliver, T.; Petersen, A.; Rambold, G.; Zeller, U.; Austermühle, R.; Bausch, J.; Bösing, B.M.; Classen, N.; Dorendorf, J.; Dorigo, W.; Esler, K.J.; Etzold, S.; Graiff, A.; Grotehusmann, L.; Hecht, J.; Hoyer, P.; Kongor, R.Y.; Lang, H.; Lieckfeld, L.A.B.; Oldeland, J.; Peters, J.; Röwer, I.U.; September, Z.M.; Sop, T.K.; van Rooyen, M.W.; Weber, J.; Willer, J.; Jürgens, N. (2010): The BIOTA Observatories. - In: Jürgens, N.; Haarmeyer, D.H.; Luther-Mosebach, J.; Dengler, J.; Finckh, M. \& Schmiedel, U. (eds.): Biodiversity in southern Africa 1: Patterns at local scale - the BIOTA Observatories. Klaus Hess Publishers, Göttingen \& Windhoek. pp. 7-801.

Harte, J.; Smith, A.B. \& Storch, D. (2009) Biodiversity scales from plots to biomes with a universal species-area curve. Ecology Letters, 12, 789-797.

He, F. \& Legendre, P. (1996) On species-area relations. The American Naturalist, 148, 719-737.

Hiernaux, P. (1998) Effects of grazing on plant species composition and spatial distribution in rangelands of the Sahel. Plant Ecology, 138, 191-202.

Hothorn, T.; Hornik, K.; van de Wiel, M.A. \& Zeileis, A. (2008) Implementing a Class of Permutation Tests: The coin Package. Journal of Statistical Software, 28, 1-23. 
Huston, M.A. (1999) Local processes and regional patterns: appropriate scales for understanding variation in the diversity of plants and animals. Oikos, 86, 393-401.

Illius, A. W. \& O’Connor, T. G. (1999) On the Relevance of Nonequilibrium Concepts to Arid and Semiarid Grazing Systems. Ecological Applications, 9, 798-813.

Jürgens, N.; Hoffman, M.T. \& Schmiedel, U. (2010) BIOTA Southern Africa. - In: Jürgens, N.; Haarmeyer, D.H.; Luther-Mosebach, J.; Dengler, J.; Finckh, M. \& Schmiedel, U. (eds.): Biodiversity in southern Africa 1: Patterns at local scale - the BIOTA Observatories. Klaus Hess Publishers, Göttingen \& Windhoek. p. 1.

Jürgens, N.; Schmiedel,U.; Haarmeyer, D.H.; Dengler, J.; Finckh, M.; Goetze, D.; Gröngröft, A.; Hahn-Hadjali, K.; Koulibaly; A.; Luther-Mosebach, J.; Muche, G.; Oldeland, J.; Petersen, A.; Porembski, S.M.; Rutherford, C.; Schmidt, M.; Sinsin, B.; Strohbach, B. J.; Thiombiano, A.; Wittig, R. \& Zizka, G. (submitted) The BIOTA Biodiversity Observatories in Africa - A standardized framework for large-scale environmental monitoring, Environmental Monitoring and Assessment.

Kier, G.; Mutke, J.; Dinerstein, E.; Ricketts, T.H.; Kuper, W.; Kreft, H. \& Barthlott, W. (2005) Global patterns of plant diversity and floristic knowledge. Journal of Biogeography, 32, $1107-1116$.

Klimeš, L.; Dančák, M.; Hájek, M.; Jongepierová, I. \& Kučera, T. (2001) Scale-dependent biases in species counts in a grassland. Journal of Vegetation Science, 12, 699-704.

Kluth, C. \& Bruelheide, H. (2004) Using standardized sampling designs from population ecology to assess biodiversity patterns of therophyte vegetation across scales. Journal of Biogeography, 31, 363-377.

Lepš, J. \& Hadincová, V. (1992) How reliable are our vegetation analyses? Journal of Vegetation Science, 3 119-124.

Lomolino, M.V. (2000) Ecology's most general, yet protean pattern: the species-area relationship. Journal of Biogeography, 27, 17-26.

Lomolino, M.V. (2001) The species-area relationship: new challenges for an old pattern. Progress in Physical Geography, 25, 1-21.

MacArthur, R.H. \& Wilson, E.O. (1967) The theory of island biogeography. Princeton University Press, Princeton.

Magurran, A.E. (2004) Measuring biological diversity. Blackwell Publishing, Oxford.

Manly, B.F.J. (2007) Randomization, Bootstrap and Monte Carlo Methods in Biology. Texts in Statistical Science, Chapman \& Hall/CRC, Boca Raton.

May, R.M. (1988) How many species on earth? Science, 241, 1441-1449.

Mendelsohn, J.; Jarvis, A.; Roberts, C. \& Robertson, T. (2009) Atlas of Namibia: A Portrait of the Land and its People. 3rd edn., Sunbird publishers, Cape Town. 
Milton, S.J.; Dean, W.R.J.; du Plessis, M.A. \& Siegfried, W.R. (1994) A conceptual model of arid rangeland degradation. The escalating cost of declining productivity. Bioscience, 44, 70-76.

Muche, G.; Jürgens, N.; Finckh, M. \& Schmiedel, U. (2010a): BIOTABase - Software for monitoring of biodiversity and environmental data. Version 27.08.2010.

Muche, G.; Hillmann, T.; Suwald, A. \&Jürgens, N. (2010b) Data access and availability: BIOTA Data Facility. - In: Schmiedel, U. \& Jürgens, N. (eds.): Biodiversity in southern Africa 2:

Patterns and processes at regional scale. Klaus Hess Publishers, Göttingen \& Windhoek. pp. 337-342.

Naveh, Z. \& Whittaker, R.H. (1979): Structural and Floristic Diversity of Shrublands and Woodlands in Northern Israel and Other Mediterranean Areas. Vegetatio, 41, 171-190.

Nichols, W.F.; Killingbeck, K.T. \& August, P.V. (1998) The influence of geomorphological heterogeneity on biodiversity. II. A landscape perspective. Conservation Biology, 12, 371379.

Nilsson, I.N. \& Nilsson, S.G. (1985) Experimental estimates of census efficiency and pseudoturnover on islands: error trend and between-observer variation when recording vascular plants. Journal of Ecology, 73, 65-70.

Noy-Meir, I.; Gutman, M. \& Kaplan, Y. (1989) Responses of Mediterranean grassland plants to grazing and protection. Journal of Ecology, 77, 290-310.

Olff, H. \& Ritchie, M.E. (1998) Effects of herbivores on grassland plant diversity. Trends in Ecology and Evolution, 13, 261-265.

Palmer, A.R. \& Hoffman, M.T. (1997) Nama Karoo. In: Cowling, R. M.; Richardson, D.M.; Pierce, S. (eds), Vegetation of southern Africa. Cambridge University Press, Cambridge. pp. 167-189.

Palmer, M. W. (1990): The estimation of species richness by extrapolation. Ecology, 71, 11951198.

Palmer, M.W. (1991) Estimating species richness: the second-order Jackknife reconsidered. Ecology, 72, 1512-1513.

Palmer, M. W. (1995) How should one count species? Natural Areas Journal, 15, 124-135.

Peet, R.K.; Wentworth, T.R. \& White, P.S. (1998) A flexible, multipurpose method for recording vegetation composition and structure. Castanea, 63, 262-274.

Petersen, A. (2008) Pedodiversity of Southern African drylands. $\mathrm{PhD}$ thesis. University of Hamburg, Hamburg.

Pielou, E. C. (1966) The measurement of diversity in different types of biological collections. Journal of Theoretical Biology, 13, 131-144. 
Plotkin, J.B.; Potts, M.D.; Yu, D.W.; Bunyavejchewin, S.; Condit, R.; Foster, R.; Hubbell, S.P.; LaFrankie, J.; Manokaran, N.; Seng, L.H.; Sukumar, R.; Nowak, M.A. \& Ashton, P.S. (2000) Predicting species diversity in tropical forests. Proceedings of the National Academy of Sciences USA, 97, 10850-10854.

Ponzetti, J.M. \& McCune, B.P. (2001) Biotic Soil Crusts of Oregon's Shrub Steppe: Community Composition in Relation to Soil Chemistry, Climate, and Livestock Activity. The Bryologist, 104, 212-225.

Preston, F.W. (1948) The commonness and rarity of species. Ecology, 29, 254-283.

Preston, F.W. (1962) The canonical distribution of commonness and rarity: part I. Ecology, 43, $187-215$.

R Development Core Team (2008) R: a language and environment for statistical computing. $\mathrm{R}$ Foundation for Statistical Computing, Vienna. (http://www.R-project.org).

Roberts, D.W. (2010) labdsv: Ordination and Multivariate Analysis for Ecology. R package version 1.4-1. (http://ecology.msu.montana.edu/labdsv/R).

Rogers, K.H. (1997) Freshwater wetlands. In: Cowling, R. M.; Richardson, D.M.; Pierce, S. (eds), Vegetation of southern Africa. Cambridge University Press, Cambridge. pp. 322-347.

Rosenzweig, M.L. (1995) Species diversity in space and time. Cambridge University Press, Cambridge.

Rowell, D.L. (1997) Bodenkunde - Untersuchungsmethoden und ihre Anwendung (Soil science - analyses methods and its application (in German)). Springer-Verlag Berlin Heidelberg.

Schaare-Schlüterhof, O. (2008) Vergleichende Studien zur Biodiversität und Habitatheterogenität auf ausgewählten BIOTA-Observatorien in Namibia (Comparative study on biodiversity and habitat heterogenity on two selected BIOTA-Observatories in Namibia (in German)). Unpublished Thesis. University of Hamburg, Hamburg.

Scheiner, S.M. (2003) Six types of species-area curves. Global Ecology and Biogeography, 12, 441447.

Scheiner, S.M. (2009) The terminology and use of species-area relationships: a response to Dengler (2009). Journal of Biogeography, 36, 2005-2008.

Schmiedel, U.; Dengler, J.; Luther-Mosebach, J.; Gröngröft, A.; Muche, G.; Petersen, A.; Strohbach, B. \& Jürgens, N. (2010) Patterns and dynamics of vascular plant diversity along the BIOTA transects in southern Afrika. - In: Jürgens, N.; Haarmeyer, D.H.; LutherMosebach, J.; Dengler, J.; Finckh, M. \& Schmiedel, U. (eds.): Biodiversity in southern Africa 2: Patterns and processes at regional scale. Klaus Hess Publishers, Göttingen \& Windhoek. pp 118-135.

Scott, L.; Anderson, H.M. \&Anderson, J.M. (1997) Vegetation history. In: Cowling, R. M.; Richardson, D.M.; Pierce, S. (eds), Vegetation of southern Africa. Cambridge University Press, Cambridge, pp. 62-84. 
Shannon, C.E. \& Weaver, W. (1949): The Mathematical Theory of Communication. University of Illinois Press, Urbana.

Shmida, A. (1984) Whittaker's plant diversity sampling method. Israel Journal of Botany, 33, 4146.

Skov, F. \& Lawesson, J.E. (2000) Estimation of plant species richness from systematically placed plots in a managed forest ecosystem. Nordic Journal of Botany, 20, 477-483.

Smith, A.B. (2010) Caution with curves: caveats for using the species-area relationship in conservation. Biological Conservation, 143, 555-564.

Smith, E.P. \& van Belle, G. (1984) Nonparametric estimation of species richness. Biometrics, 40, 119-129.

Sober, E. (1981) The principle of parsimony. British Journal of Philosophy Science; 32, 145-156.

Stiles, A. \& Scheiner, S.M. (2007) Evaluation of species-area functions using Sonoran Desert plant data: not all species-area curves are power functions. Oikos, 116, 1930-1940.

Stohlgren, T.J.; Falkner, M.B. \& Schell, L.D. (1995) Modified Whittaker nested vegetation sampling method. Vegetatio, 117, 113-121.

Stout, R.J. \& Vandermeer, J.H. (1975) Comparison of species richness for stream-inhabiting insects in tropical and mid-latitude streams. The American Naturalist, 100, 263-280.

Thompson G.G. \& Withers P.C. (2003) Effect of species richness and relative abundance on the shape of the species accumulation curve. Australian Journal of Ecology, 28, 355-360.

Tjørve, E. (2003) Shapes and functions of species-area curves: a review of possible models. Journal of Biogeography, 30, 827-835.

Todd, S.W. \& Hoffman, M.T. (1999) A fence-line contrast reveals effects of heavy grazing on plant diversity and community composition in Namaqualand, South Africa. Plant Ecology, $142,169-178$.

UNEP [United Nations Environment Programme] (1992) Convention on biological diversity. United Nations Environment Programme, Nairobi.

Vittoz, P. \& Guisan, A. (2007) How reliable is the monitoring of permanent vegetation plots? A test with multiple observers. Journal of Vegetation Science, 18, 413-422.

Walker, B.H.; Ludwig, D.; Holling, C.S. \& Peterman, R.M. (1981) Stability of semi-arid savanna grazing systems. Journal of Ecology, 69, 473-498.

Walther, B.A. \& Moore, J.L. (2005) The definitions of bias, precision, and accuracy, and their use in testing the performance of species richness estimators, with a literature review of estimator performance. Ecography, 28, 815-829.

Waser, N.M. \& Price, M.V. (1981) Effects of grazing on diversity of annual plants in the Sonoran Desert. Oecologia, 50, 407-411. 
Wei, S.-H.; Li, L.; Walther, B. A.; Ye, W.-H.; Huang, Z.-l.; Cao, H.-L.; Lian, J.-Y.; Wang, Z.G.; Chen, Y.-Y. (2010) Comparative performance of species-richness estimators using data from a subtropical forest tree community. Ecological Research, 25, 93-101.

Westhoff, V. \& van der Maarel, E. (1978) The Braun-Blanquet approach. 2nd ed. In: R.H. Whittaker (ed). Classification of plant communities. Junk, The Hague. pp. 287-399.

Williams, M.R. (1995) An Extreme-Value Function Model of the Species Incidence and SpeciesArea Relations. Ecology, 76, 2607-2616. 


\section{List of Figures}

Figure 2-1: Map of the BIOTA Southern Africa transect and satellite picture of BIOTA Observatories Narais and Duruchaus with sampling plots of this study (green squares) and highlighted fence line contrast. (sources: BIOTA Africa, Hymap Satellite Picture 2005, edited).

Figure 2-2: Climate diagram of the BIOTA Observatory Narais, central Namibia (source: HAARMEYER et al., 2010; data: 2004-2009).

Figure 2-3: Fence line contrast separating the Observatories Narais (on the left) and Duruchaus (on the right) (photo D. Wesuls, 2009).

Figure 2-4: a) Landscape impression of the study area (Observatory Duruchaus), b) Vegetation sampling design. Threefold replicated nested plot design. $0.01-$ and $0.1-\mathrm{m}^{2}$ scales are not shown

Figure 3-1: Boxplots of species richness per sampling scale for both Observatories (total) and separated for Narais (NA) and Duruchaus (DU)....

Figure 3-2: Extrapolation of selected SAR functions to $1 \mathrm{~km}^{2}$ (for better presentation in log-logtransformation which was not used for curve fitting). .20

Figure 3-3: Extrapolation of selected SSR functions to $1 \mathrm{~km}^{2}$ (스 1000 samples à $\left.1000 \mathrm{~m}^{2}\right)$ for the Observatories Narais (NA) and Duruchaus (DU)....

Figure 3-4: Species accumulation curves and curves of non-parametric species richness estimators of the Observatories Narais (NA) and Duruchaus (DU)....

Figure 4-1: Impression of vegetation composition on the Observatories Narais (NA) and Duruchaus (DU)

Figure 5-1: Species richness of the sampled 1-ha plots determined in the BIOTA monitoring in 2009, accumulated from 2005 to 2009 in the BIOTA monitoring, with the extensive sampling of this study, and estimated with the saturation value of rational models based on the extensive sampling.....

Figure 5-2: Level of exhaustiveness per sampling time effort shown in 5-min intervals for the average of ten sampled 1-ha plots and for three exemplary plots of extensive sampling: D-51 as species rich plot with low exhaustiveness, D-63 as species poor plot with intermediate exhaustiveness, and D-82 as also species poor plot with high exhaustiveness. .48 


\section{List of Tables}

Table 3-1: Overview of the models used for fitting species-area and species-sampling relationships.

Table 3-2: Overview over applied non-parametric richness estimators with $S_{\text {obs }}=$ total number of observed species, $\mathrm{Q}_{j}=$ number of species that occur in exactly $j$ samples, $\mathrm{m}=$ total number of samples, $\mathrm{p}_{k}=$ proportion of samples that contain species $k$.

Table 3-3: Ranking of fitted species-area relation (SAR) models to the applied goodness-of-fit metrics. Mean rank of both metrics ( $\triangle \mathrm{AICc}, \mathrm{LEE}$ ), Rank $\triangle \mathrm{AICc}$, Rank LEE, mean values of $\triangle \mathrm{AICc}$, LEE, and $\mathrm{w}_{\mathrm{i}}$ for all plots.

Table 3-4: Ranking and mean $\triangle$ AICc of applied SSR models.

Table 3-5: Vascular plant species richness estimated for the area $\left(1 \mathrm{~km}^{2}\right)$ of the Observatories with different methods. The methods grouped into four categories: (1) Data from sampling, (2) Extrapolation of species-area relationships (SARs), (3) Extrapolation of species-sampling relationships (SSRs), and (4) Non-parametric Estimators..

Table 4-1: Average species richness of different sampled scales for the total study area and separated for the Observatories Narais and Duruchaus. The absolute minimum and maximum richness is given for all plots of the referred size. The significance level of the two-samples permutation tests (p-values) is given for the difference between averages of the Observatories $(n=20)$......

Table 4-2: List of indicator species of Narais Observatory with the constancy of occurrence on the Observatory, the indicator value (IndVal) after DufrêNE \& LEGENDRE (1997) and the p-value of IndVal.

Table 4-3: List of indicator species of Duruchaus Observatory with the constancy of occurrence on the Observatory, the indicator value (IndVal) after Dufrêne \& Legendre (1997) and the p-value of IndVal.

Table 4-4: Average $z$-values of the slope between different spatial scales and significance level of twosamples permutation tests (p-values) $(n=20)$.

Table 4-5: Average values of environmental parameters for the Observatories Narais and Duruchaus and significance level of two-samples permutation tests (p-values) $(n=20)$.

Table 4-6: Average values of vegetation parameters for the Observatories Narais and Duruchaus and significance level of two-samples permutation tests (p-values) $(n=20)$......

Table 5-1: Overview of asymptotic functions used to fit the species-effort relationship.

Table 5-2: Ranking and mean saturation level of applied saturation models according to the goodnessof-fit measurements $\triangle \mathrm{AICc}$ and LEE.

Table 5-3: Table 5-3: Table of record frequencies of overlooked vascular plant species at ten sampled 1ha plots in this study and in the BIOTA monitoring from 2009, their rate of detection, and their plant functional traits. All species for which the BIOTA sampling reported $\leq 25 \%$ of the actual occurrences are shown. 


\section{List of Abbreviations}

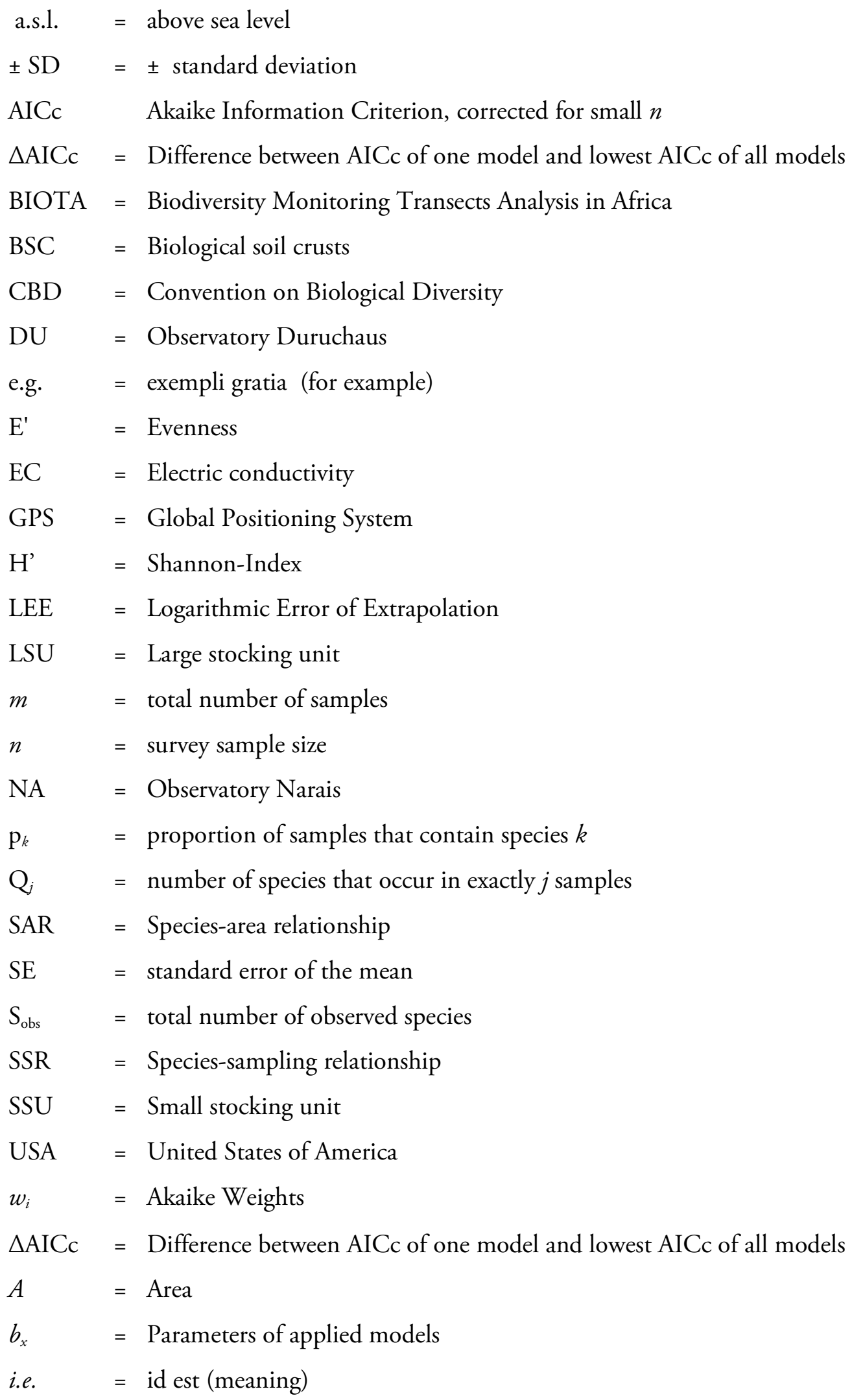




\section{Digital Appendix (on attached Compact Disc)}

D-Annex 1 BIOTAbase-database of all sampled plots (vegetation and habitat data)

D-Annex 2 Table of sampled environmental parameters at $100-\mathrm{m}^{2}$ plots ( ${ }^{*}$.xls-file)

D-Annex 3 Photo documentation of all sampled plots

D-Annex 4 Tables of goodness-of-fit measurement and extrapolation figures for each sampled plot and applied methods for SARs, SSRs, and extensive sampling and detailed data of non-parametric estimators (*.xls-files)

D-Annex 5 Digital version of this thesis (*.pdf-file)

D-Annex $6 \quad$ Setup file of BIOTAbase program (version date 27.09.2010)

Correspondence:

Jan Peters

Anklamer Straße 77

D-17489 Greifswald

Germany

E-mail: janpeters-ol@web.de 


\section{Erklärung zur Diplomarbeit}

Hiermit erkläre ich, die vorliegende Diplomarbeit mit dem Thema

„Plant diversity pattern at different spatial scales

in a semi-arid savanna ecosystem in central Namibia"

selbstständig verfasst und keine anderen Hilfsmittel als die angegebenen verwendet zu haben. Aus anderen Werken in Wortlaut oder Sinngehalt entnommene Inhalte sind durch Quellenverweis, auch für Sekundärliteratur, kenntlich gemacht.

Greifswald, den 08.10.2010

Jan Peters 